\title{
Dynamic compressive behavior of ice at cryogenic temperatures
}

\author{
Xianqian $\mathrm{Wu}^{\mathrm{b}}$, Vikas Prakash ${ }^{\mathrm{a}, *}$ \\ a Department of Mechanical and Aerospace Engineering, Case Western Reserve University, Cleveland, OH 44106, USA \\ ${ }^{\mathrm{b}}$ Key Laboratory of Mechanics in Fluid Solid Coupling Systems, Institute of Mechanics, Chinese Academy of Sciences, Beijing 100190, PR China
}

\section{A R T I C L E I N F O}

Article history:

Received 20 September 2014

Received in revised form 2 June 2015

Accepted 9 June 2015

Available online 15 June 2015

\section{Keywords:}

Dynamic compression of ice

Low temperature split Hopkinson pressure bar Rate sensitivity of ice

Cryogenic temperatures

Peak stress

\begin{abstract}
A B S T R A C T
In the present study dynamic behavior of distilled water ice (polycrystalline ice $\mathrm{Ih}$ ) is investigated under uniaxial compression at strain rates in the range of $100 \mathrm{~s}^{-1}$ to $1350 \mathrm{~s}^{-1}$ and at temperatures in the range of $-15^{\circ} \mathrm{C}$ to $-173^{\circ} \mathrm{C}$ using a modified split Hopkinson pressure bar (SHPB). The peak compressive strength is found to increase from $32 \mathrm{MPa}$ to $112 \mathrm{MPa}$ as the test temperatures are decreased from $-15^{\circ} \mathrm{C}$ to $-125^{\circ} \mathrm{C}$. With a further decrease in test temperature from $-125^{\circ} \mathrm{C}$ to $-173^{\circ} \mathrm{C}$ the peak strength is observed to remain nearly constant and lie in the range of $110-120 \mathrm{MPa}$. In addition, the ice samples show positive strain rate sensitivity over the range of strain rates employed in the present tests at test temperatures in the range of $-15^{\circ} \mathrm{C}$ to $-125^{\circ} \mathrm{C}$. However, the sensitivity of the logarithmic of peak stress (strength) to logarithmic of strain rate decreases with decreasing test temperatures, and the ice samples are observed to be nearly insensitive to strain rate at test temperatures lower than $-125^{\circ} \mathrm{C}$. An interesting feature of the dynamic compressive behavior of ice is the presence of a shoulder/double-peak in the dynamic stress versus strain curves at test temperatures in the range of $-50{ }^{\circ} \mathrm{C}$ to $-150{ }^{\circ} \mathrm{C}$. Another feature of the post-peak stress regime of distilled water ice is the presence of a long tail in the dynamic stress versus strain curves at a test temperature of $-15^{\circ} \mathrm{C}$. At lower test temperatures (from $-150^{\circ} \mathrm{C}$ to $-173^{\circ} \mathrm{C}$ ) the residual strength of ice is observed to become negligible. These artifacts in the dynamic behavior of ice can be attributed to details associated with dynamic failure of the ice samples and geometric effects emanating from the finite size of the samples and the diameter of the loading bars. The residual dynamic strength of ice can be best understood by considering the damaged/fragmented ice as an assemblage of wet highly-fragmented granular material created by adiabatic heating during grain-to-grain frictional sliding and held together by ice melt and/or recrystallization in the post peak-stress regime.
\end{abstract}

(c) 2015 Elsevier B.V. All rights reserved.

\section{Introduction}

Many fundamental questions regarding preservation of Europa's evolutionary history and possibility of finding life can be best examined by performing in-situ analysis of its ice and oceans (Carr et al., 1998). In this context, a mission to the Jupiter's moon Europa to search for life in its ice-covered oceans promises to provide a unique opportunity to place scientific instruments onto the surface of Europa. Compared with conventional soft-landers that have previously been used in Lunar and Mars explorations, high-velocity kinetic penetrators provide the benefit to access the sub-surface of Europa for onsite sampling and analysis without the need for additional drilling or digging. Moreover, kinetic energy penetrators have the advantage of simplicity and require no sophisticated landing programs for the airless environment on Europa. One of the key challenges faced in the mission is to enable deep

\footnotetext{
* Corresponding author. Tel.: +1 2168342646.

E-mail address: vikas.prakash@case.edu (V. Prakash).
}

penetration of the cryogenic ice crust of Europa to deliver the required scientific instruments for in-situ analysis of the subsurface layers which necessitates a better understanding of the basic impact physics into cryogenic ice. For example, the fundamental thermo-mechanical properties of hard cryogenic ice determine the boundary conditions acting on the projectile, and significantly affect the stress state, peak loads, accelerations, and penetration depth of the penetrator.

There is a considerable body of literature that addresses the dynamic compressive behavior of ice at strain rates in the range from $10^{-2} \mathrm{~s}^{-1}$ to $2600 \mathrm{~s}^{-1}$ and at temperatures in the range from $0{ }^{\circ} \mathrm{C}$ to $-30^{\circ} \mathrm{C}$. However, there is little data on the dynamic behavior of ice at cryogenic temperatures in the range from sub-zero to $-170{ }^{\circ} \mathrm{C}$. In view of this, an experimental investigation was undertaken at Case Western Reserve University to obtain the dynamic uniaxial compressive strength and failure of ice as a function of loading rate (up to $1500 \mathrm{~s}^{-1}$ ) and test temperatures down to $-173^{\circ} \mathrm{C}$. The data obtained from the present study can be used to validate and/or develop new material models for dynamic behavior of ice at high strain rates and cryogenic temperatures for various planetary and/or engineering applications.

The mechanical behavior of ice is complex. Ice, that can be regarded as a class of materials rather than a single specific material with well- 
defined properties, has thirteen different crystal structures and two amorphous states depending upon its growth temperature and pressure conditions (Klug, 2002; Petrenko and Whitworth, 1999). A relatively large body of literature exists on the compressive and tensile behavior (Currier and Schulson, 1982; Dempsey et al., 1999a; Dempsey et al., 1999b; Haynes, 1978; Jones and Glen, 1969; Petrenko and Whitworth, 1999; Schulson, 2001; Schulson and Duval, 2009; Schulson and Gratz, 1999; Schulson et al., 2005), and fracture properties (Dempsey, 1991; Nixon and Schulson, 1987; Parameswaran and Jones, 1975; Schulson, 1990; Schulson and Duval, 2009; Uchida and Kusumoto, 1999; Weber and Nixon, 1996) of ice. Most of these studies focus on the creep and quasi-static deformation behavior of distilled water ice. Like many brittle materials, ice is stronger in compression than in tension. However, unlike most brittle materials, ice exhibits brittle behavior up to its melting point even at relatively low strain rates (Schulson, 2001).

The compressive strength of ice is sensitive to strain rate and ice exhibits behavior ranging from ductile to brittle under various loading rates. The ductile to brittle transition is understood to occur at a strain rate of $10^{-3} \mathrm{~s}^{-1}$ at a test temperature of $-10^{\circ} \mathrm{C}$. At higher strain rates, there are relatively few studies on the compressive behavior of ice. The studies by Dutta (1993) and Dutta et al. (2004) suggest that the compressive strength of ice at high strain rates is lower than that obtained under quasi-static deformation conditions. Kim and Keune (2007), using the split Hopkinson pressure bar (SHPB) (Hopkinson, 1914; Kolsky, 1949), reported that the compressive strength of ice is essentially constant at a level of $19.7 \mathrm{MPa}$ in the strain rate range of 400 to $2600 \mathrm{~s}^{-1}$. Other studies on ice at high strain rates indicate that its compressive strength shows positive strain rate sensitivity. For example, study by Jones (1997) show that the compressive strength of ice increases with increasing loading rates over the strain rate range $10^{-1}$ to $10 \mathrm{~s}^{-1}$, although the data shows considerable scatter. The study by Schulson et al. (2005) shows similar behavior in the strain rate range from $10^{-2}$ to $1.6 \mathrm{~s}^{-1}$. In a more recent study, Shazly et al. (2006b, 2009 ) investigated the dynamic behavior of single crystal and polycrystalline ice using SHPB at a range of strain rates from 60 to $1400 \mathrm{~s}^{-1}$. The compressive strengths of both single and polycrystalline ice samples were reported to increase with increasing strain rates. The compressive strength of ice have also been reported to be sensitive to temperature. Studies by Carter et al. (1971) and Schulson et al. (2005) show that the compressive strength of ice increases linearly with decreasing temperatures by approximately $0.3 \mathrm{MPa} / \mathrm{K}$ over the temperature range from $0{ }^{\circ} \mathrm{C}$ to $-50{ }^{\circ} \mathrm{C}$ under quasi-static deformation conditions. In addition, Arakawa and Maeno (1997) have shown that under quasi-static uniaxial compression the sensitivity of compressive strength of ice to test temperature is positive in the temperature range from $0{ }^{\circ} \mathrm{C}$ to $-100{ }^{\circ} \mathrm{C}$, and then the compressive strength becomes nearly constant in the temperature range from $-100{ }^{\circ} \mathrm{C}$ to $-175^{\circ} \mathrm{C}$.

In view of the aforementioned studies the compressive behavior of ice can be summarized as follows. Under quasi-static uniaxial compression the strength of ice increases from $3 \mathrm{MPa}$ to $65 \mathrm{MPa}$ with a decrease in test temperature from $0{ }^{\circ} \mathrm{C}$ to $-100{ }^{\circ} \mathrm{C}$ and then increases rather slowly from $65 \mathrm{MPa}$ to $75 \mathrm{MPa}$ from $-100{ }^{\circ} \mathrm{C}$ to $-175{ }^{\circ} \mathrm{C}$. On the other hand, under high loading rates the uniaxial compressive strength of ice is observed to increase with increasing strain rates in the range 60 to $2000 \mathrm{~s}^{-1}$ and at test temperatures in the range $-10^{\circ} \mathrm{C}$ to $-30{ }^{\circ} \mathrm{C}$. Arakawa and Maeno (1997) have attributed the insensitivity of quasistatic compressive strength of ice at test temperatures lower than $-50{ }^{\circ} \mathrm{C}$ to possible confinement of specimen end faces due to adhesion/freezing of the ice samples to the loading platens. At higher loading rates, however, the end face confinement is negligibly small as per analysis provided by Shazly et al. (2006b, 2009). Therefore, one of the key motivations of the present study is to better understand whether this observed insensitivity of compressive strength with a decrease in test temperature at quasi-static loading rates is carried over to the higher loading rate condition.
In this regards, in the present study, the conventional split Hopkinson pressure bar is modified to accommodate experimentation on ice at cryogenic test temperatures and high strain rates. The paper is organized as follows: in Section 2, the experimental procedure used for the growth of the ice samples and the extension of the split Hopkinson pressure bar for cryogenic temperature testing are described. Section 3 provides details of the experimental results on ice at various strain rates and test temperatures. In Section 4, the experimental results on ice obtained at various strain rates and cryogenic temperatures are compared and a discussion relevant to the experimental results is provided.

\section{Experimental methods}

\subsection{Ice specimens}

In the present study, disk shaped ice samples were utilized to conduct the dynamic compression experiments at elevated strain rates and sub-zero temperatures down to $-175^{\circ} \mathrm{C}$. Two different ice samples were utilized in the present study. At test temperatures up to $-50^{\circ} \mathrm{C}$ ice specimens of $19.05 \mathrm{~mm}$ diameter and $3 \mathrm{~mm}$ thickness were utilized while at temperatures lower than $-50{ }^{\circ} \mathrm{C}$ ice samples of $11.23 \mathrm{~mm}$ in diameter and $\sim 3 \mathrm{~mm}$ in thickness were employed to accommodate the increase in ice compressive strength with decrease in test temperatures. Although the ice samples were thin when compared to their diameter, which could constrain radial displacements in the sample during loading and lead to concerns regarding frictional effects, previous study by Shazly et al. (2006b, 2009) have shown that the frictional/adhesion effects at the ice sample/bar ends are expected to be negligible (please refer to Appendix A) since dynamic frictional resistance between ice and aluminum inserts is relatively low at high sliding rates (Irfan and Prakash, 1994; Okada et al., 2001; Prakash and Yuan, 2004; Yuan and Prakash, 2008a; Yuan and Prakash, 2008b).

Besides frictional effects, the stress wave loading used in split Hopkinson pressure bar experiments can cause inertia to have an influence on the measured sample properties, particularly at high strain rates (Graham, 1989). For a sample with diameter d, and an initial length to diameter ratio $l_{o} / d_{o}$, the stresses measured by the output bar, $\sigma_{\text {measured }}$, can be expressed as

$$
\begin{aligned}
\sigma_{\text {measured }}-\sigma_{y}= & \rho d^{2} \dot{\varepsilon}^{2}\left[\frac{1}{64}+\frac{1}{6}\left(\frac{l_{0}}{d_{0}}\right)^{2}\right] \\
& -\rho d^{2} \ddot{\varepsilon}\left[\frac{1}{32}-\frac{1}{6}\left(\frac{l_{0}}{d_{0}}\right)^{2}\right]-\frac{\rho l \dot{v}}{2}
\end{aligned}
$$

where, $\sigma_{y}$ is the actual yield stress of the material, $\rho$ is the density of the material, ad $\mathrm{v}$ is the velocity of the interface between the specimen and

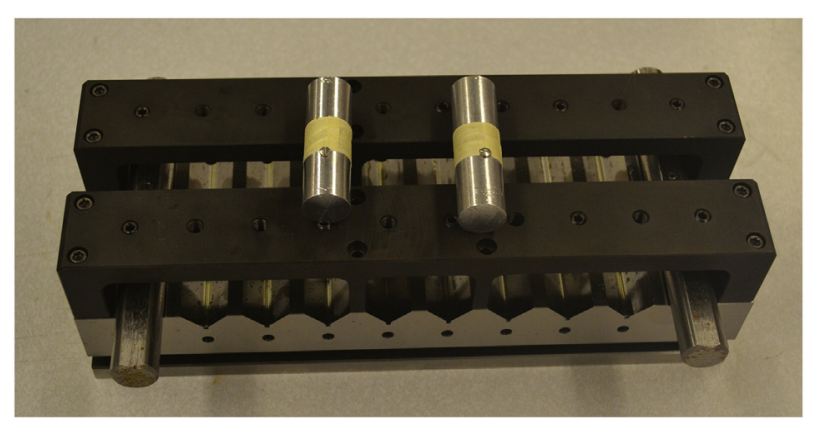

Fig. 1. Method for growing ice samples of $19.05 \mathrm{~mm}$ and $11.23 \mathrm{~mm}$ in diameter employed in the modified low temperature SHPB designed for conducting uniaxial compression experiments. Two precision matched Vee blocks are used to ensure perfect alignment (parallelism) between the two inserts. 


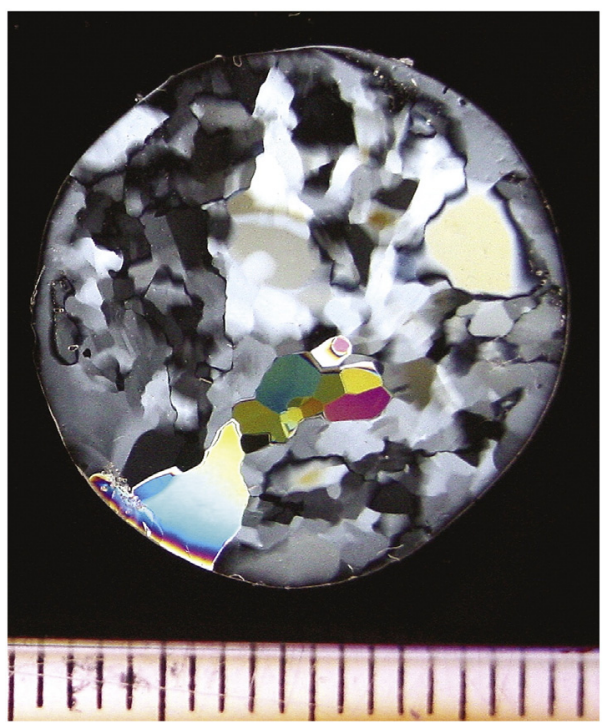

Fig. 2. Typical transverse microstructure of the ice sample. Note that the vertical lines represent the scale and the spacing between the lines is $1 \mathrm{~mm}$.

the output bar. In a typical SHPB experiment with a nearly constant strain rate, the magnitude of the second term is much smaller when compared with that of the first term, and the magnitude of the third term is generally small for materials which do not exhibit very high strain hardening and/or softening. Ignoring the second and third terms, a typical relative error in flow stress measurement due to inertia can be expressed as

$\frac{\sigma_{\text {measured }}-\sigma_{y}}{\sigma_{y}}=\frac{\rho d^{2}}{\sigma_{y}} \dot{\varepsilon}^{2}\left[\frac{1}{64}+\frac{1}{6}\left(\frac{l_{o}}{d_{0}}\right)^{2}\right]$

For the ice samples used in the present study, using Eq. (2) the error due to inertia can be approximated to be $0.001 \%$, where we have used the ice density to be $\sim 897 \mathrm{~kg} / \mathrm{m}^{3}, \& \&$ diameter of the sample $\sim 19 \mathrm{~mm}$, $l_{o} / d_{o}$ ratio of 0.16 , average strain rates $250 \mathrm{~s}^{-1}$, and $\sigma_{y} \sim 30 \mathrm{MPa}$,

As shown in Fig. 1, ice samples of $19.05 \mathrm{~mm}$ in diameter were grown between two flat aluminum inserts of corresponding diameter and $31.75 \mathrm{~mm}$ in length with smooth end-surfaces, which were spaced at a predetermined distance (equivalent to the desired thickness of the ice specimens) and then wrapped with masking tape to form a mold, whereas the disk ice samples of $11.23 \mathrm{~mm}$ in diameter were grown using a similar method except that a pair of steel inserts of $11.23 \mathrm{~mm}$ in diameter and $31.75 \mathrm{~mm}$ in length were used. The diameter of the steel inserts was selected to match the acoustic impedance of the aluminum Hopkinson bars. A small hole is introduced in the masking tape to fill the cavity between the two inserts with de-ionized water to grow ice. The hole also acts as a drain for water from the compartment when it freezes. A precision matched pair of Vee blocks were used to ensure perfect alignment between the two inserts. The whole assembly is then placed inside a freezer at $-40{ }^{\circ} \mathrm{C}$ to grow the ice samples. The ice nucleation and growth process required approximately $30 \mathrm{~min}$; however, the specimens are kept in the freezer for at least 6 more hours before the samples were taken out of the freezer for testing. Due to the high thermal conductivity of the aluminum inserts the ice crystals were observed to consistently nucleate from the inner faces of the aluminum inserts inside the molds and grow inwards towards the center of the compartment. This growth process resulted in a noticeable interface at the mid-plane of the ice specimens. Since the interface was nearly perpendicular to the axis of the disk its effect on the measured dynamic compression strength of ice was found to be negligible.

Fig. 2 shows the microstructure of a typical ice sample grown by following the aforementioned method. We observed the microstructure of the specimens by examining thin-sections under direct light and/or between crossed polarizing filters. Under polarized light, the grains exhibited interference colors and could be easily differentiated. The ice samples were found to be polycrystalline, and the ice crystals preferentially nucleated from the aluminum inserts creating small equi-axed grains up to approximately $1.5 \mathrm{~mm}$ in diameter. These grains continue to grow from the two insert ends towards the mid-plane of the sample. The resulting grains were approximately $3 \mathrm{~mm}$ in diameter by $5 \mathrm{~mm}$ in length for the largest grains. The transverse section of the ice specimen indicates that the large grains have extensive substructures. It is to be noted that the relatively large grain size relative to the thickness of the ice samples $(\sim 3 \mathrm{~mm})$ used in the present study is not expected to have any serious implications on the measured dynamic stress versus strain profiles since our previous study on dynamic behavior of ice with $3 \mathrm{~mm}$ and $6 \mathrm{~mm}$ thick ice samples with similar grain size has shown that the sample thickness to grain size ratio effect on the measured dynamic behavior is negligible (Shazly et al., 2009). Also, there were concerns that during ice growth the ice samples may have developed a crystallographic texture with ice crystals being elongated along the insert axis (longitudinal) when compared to the radial direction.

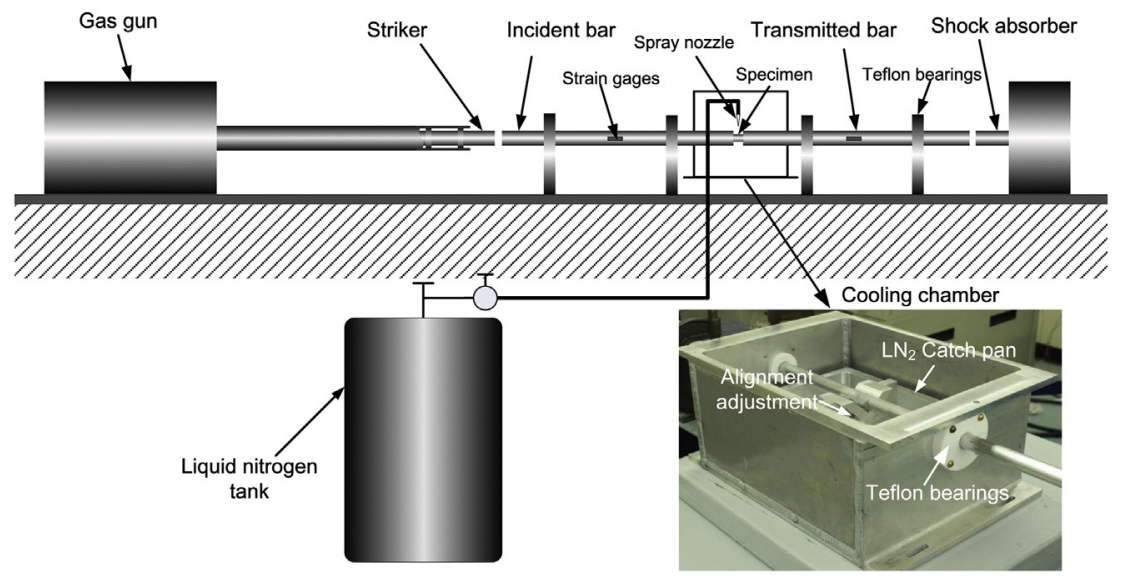

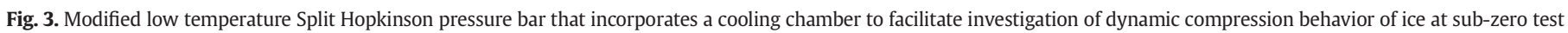
temperatures. 


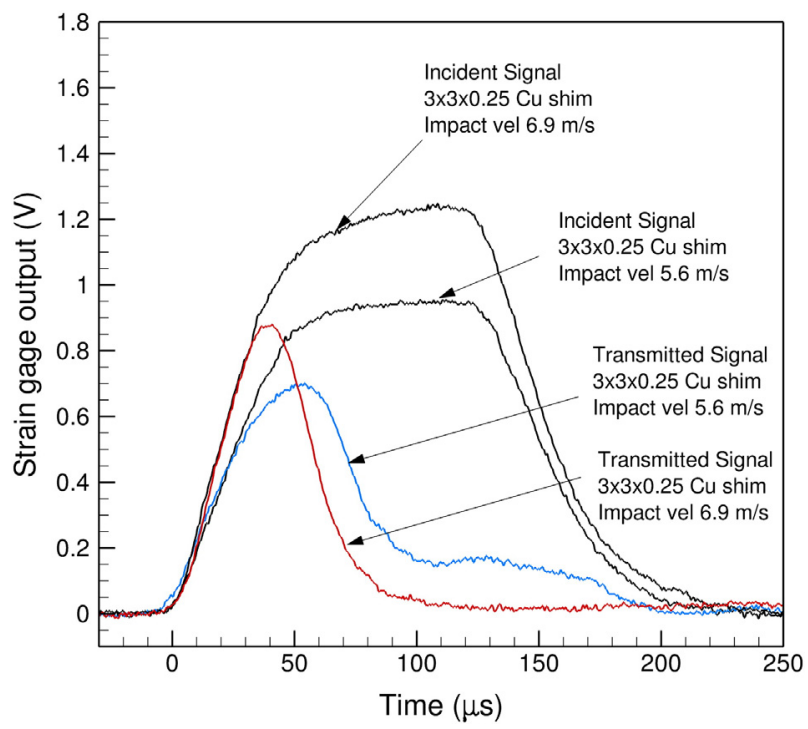

Fig. 4. Pulse shaper optimization by trial and error method to match the slopes of the incident and transmitted signals for impact velocities of 5.6 and $6.9 \mathrm{~m} / \mathrm{s}$.

Consequently, in the present study, all dynamic compression experiments were with the sample longitudinal direction being parallel to the bar direction.

\subsection{Modified split Hopkinson pressure bar}

In the present study, SHPB apparatus was modified to investigate the compressive behavior of ice at high strain rates varying from 100 to $1300 \mathrm{~s}^{-1}$ and at cryogenic temperatures in a range of $-15{ }^{\circ} \mathrm{C}$ to $-173^{\circ} \mathrm{C}$. The schematic of the modified SHPB for low temperature experiments is shown in Fig. 3 (Wu and Prakash, 2015). The facility comprises a striker bar, an incident bar, and a transmitter bar, all made from $19.05 \mathrm{~mm}$ diameter high-strength 7075-T6 aluminum alloy having a nominal yield strength of approximately $500 \mathrm{MPa}$. The length of the striker bar is about $0.3 \mathrm{~m}$, while the lengths of the incident and transmitter bars are approximately $1.8 \mathrm{~m}$ and $2 \mathrm{~m}$, respectively. The striker bar was accelerated using a compressed air gas gun to impact velocities in the range of 3 to $20 \mathrm{~m} / \mathrm{s}$; corresponding strain rates in the ice specimens

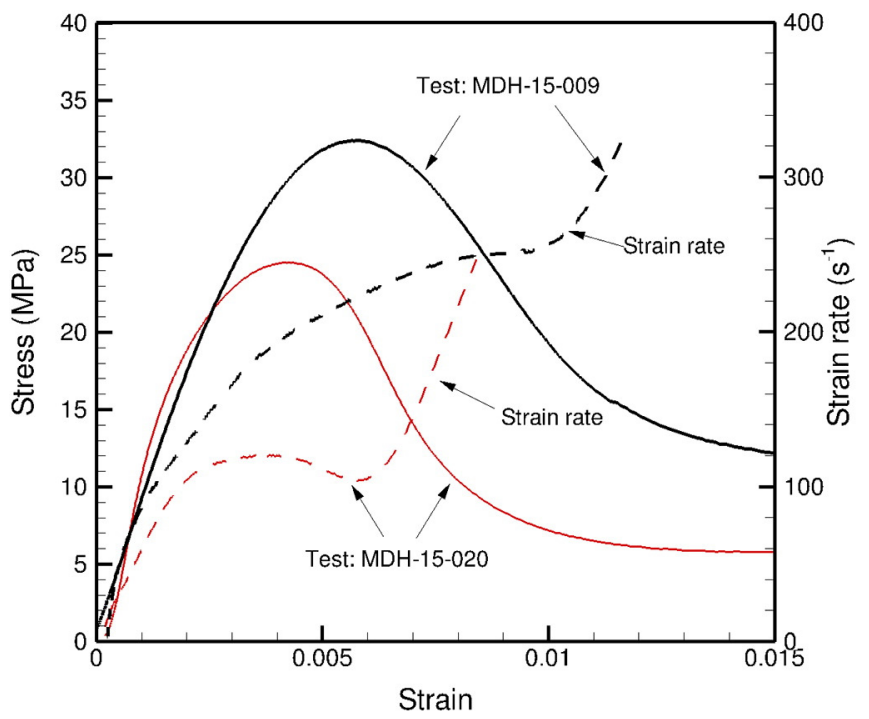

Fig. 5. Stress and strain-rate versus strain profiles for two representative experiments MDH-15-009 and MDH-15-20 at a test temperature of $-15^{\circ} \mathrm{C}$.
Table 1

Experimental parameters for tests conducted at $-15^{\circ} \mathrm{C}$.

\begin{tabular}{lllll}
\hline Test name & $\begin{array}{l}\text { Test Temp } \\
\left({ }^{\circ} \mathrm{C}\right)\end{array}$ & $\begin{array}{l}\text { Thickness } \\
(\mathrm{mm})\end{array}$ & $\begin{array}{l}\text { Pulse shaper } \\
(\mathrm{mm})\end{array}$ & Type of insert \\
\hline MDH-15-004 & -13 & 3.1 & $3 \times 3 \times 0.25$ & Aluminum inserts \\
MDH-15-008 & -13 & 2.4 & $3 \times 3 \times 0.25$ & Aluminum inserts \\
MDH-15-009 & -14 & 2.5 & $3 \times 3 \times 0.25$ & Aluminum inserts \\
MDH-15-010 & -15 & 2.5 & $3 \times 3 \times 0.25$ & Aluminum inserts \\
MDH-15-020 & -15 & 4.7 & $3 \times 3 \times 0.25$ & Aluminum inserts \\
MDH-15-021 & -14 & 3.0 & $3 \times 3 \times 0.25$ & Steel inserts \\
MDH-15-022 & -14 & 2.9 & $3 \times 3 \times 0.25$ & Steel inserts \\
MDH-15-023 & -14 & 2.8 & $3 \times 3 \times 0.25$ & Steel inserts \\
\hline
\end{tabular}

are 100 to $1300 \mathrm{~s}^{-1}$. A pair of backed semiconductor strain gages (SS-060-033-1000 PB-S1) strategically attached on to the incident and transmitter bars were utilized in combination with a Wheatstone bridge circuit, a differential amplifier (Tektronix 5A22N), and a digital oscilloscope (Tektronix TDS 420) to record the strain pulses in the incident and transmitter bars during the dynamic tests.

To enable high rate compression tests on ice at sub-zero temperatures the conventional SHPB was modified to incorporate a cooling chamber around the specimen. Also, a self-pressurized liquid nitrogen tank equipped with a nozzle spray tool was employed to direct a spray of liquid nitrogen directly on the sandwiched ice specimens between the inserts. The temperature of the specimen was monitored by a 0.015 inch diameter chromel-alumel wire thermocouple secured in a well machined screw hole by a matched aluminum bolt in one of the inserts sandwiching the ice specimen. Using this procedure, high strain rate SHPB dynamic compression tests were conducted on ice at subzero temperatures over $-15^{\circ} \mathrm{C}$ to $-173^{\circ} \mathrm{C}$.

In a typical SHPB test, a compressed air gas gun was used to accelerate the striker bar to impact the incident bar at a pre-determined velocity. The impact results in an elastic compression wave with a strain profile $\varepsilon_{I}(t)$, which travels in the incident bar towards the specimen. Due to the impedance mismatch between the specimen and the pressure bars, part of the incident compressive wave is reflected back into the incident bar, denoted by $\varepsilon_{R}(t)$, while the rest, denoted by $\varepsilon_{T}(t)$, is transmitted through the specimen into transmitter bar. Under the assumption of homogeneous deformation, elementary 1D elastic wavepropagation equations are used to calculate the engineering stress $\sigma_{S}(t)$, the strain rate $\dot{\varepsilon}_{S}(t)$, and strain $\varepsilon_{S}(t)$ in specimen as

$$
\begin{aligned}
& \sigma_{S}(t)=E \frac{A_{0}}{A_{S}} \varepsilon_{T}(t) \\
& \dot{\varepsilon}_{S}(t)=-2 \frac{c_{0}}{L_{S}} \varepsilon_{R}(t) \\
& \varepsilon_{S}(t)=\int_{0}^{t} \dot{\varepsilon}_{S}(t) d t
\end{aligned}
$$

Table 2

Experimental results for tests conducted at $-15{ }^{\circ} \mathrm{C}$

\begin{tabular}{lllll}
\hline Test name & $\begin{array}{l}\text { Impact velocity } \\
(\mathrm{m} / \mathrm{s})\end{array}$ & $\begin{array}{l}\text { Strain rate } \\
\left(\mathrm{s}^{-1}\right)\end{array}$ & $\begin{array}{l}\text { Strain at peak stress } \\
\left(\times 10^{-3}\right)\end{array}$ & $\begin{array}{l}\text { Peak stress } \\
(\mathrm{MPa})\end{array}$ \\
\hline MDH-15-004 & 5.1 & 119 & 7.7 & 26.6 \\
MDH-15-008 & 5.2 & 156 & 7.9 & 25.7 \\
MDH-15-009 & 7.0 & 224 & 5.9 & 32.4 \\
MDH-15-010 & 7.0 & 272 & 7.5 & 33.6 \\
MDH-15-020 & 5.0 & 117 & 4.0 & 24.5 \\
MDH-15-021 & 1.9 & 100 & 5.3 & 26.8 \\
MDH-15-022 & 2.5 & 118 & 4.7 & 28.4 \\
MDH-15-023 & 3.0 & 175 & 3.5 & 30.9 \\
\hline
\end{tabular}




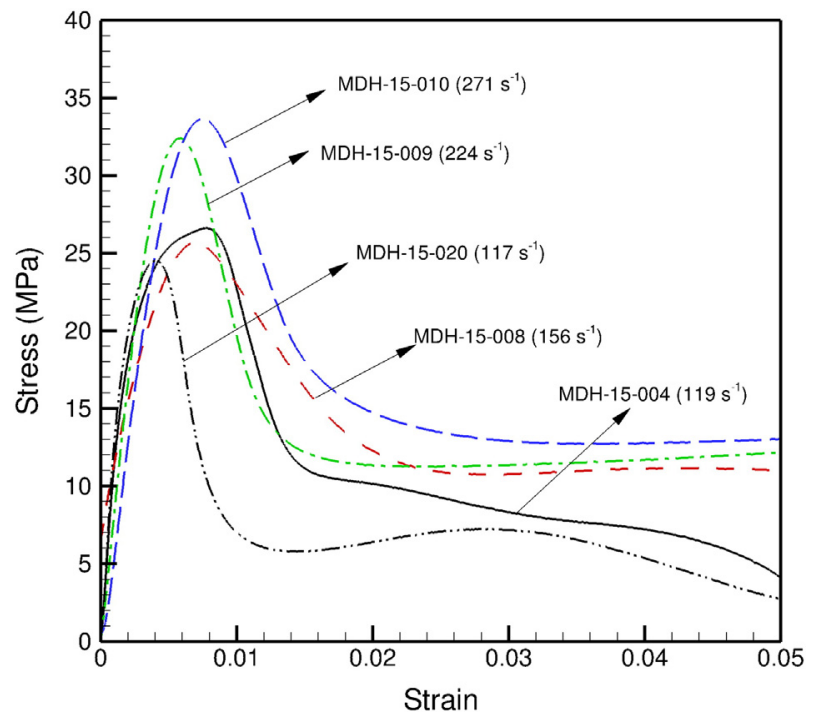

Fig. 6. Stress versus strain profiles for uniaxial compression on distilled water ice grown using aluminum inserts at a test temperature of $-15^{\circ} \mathrm{C}$.

In Eqs. (3) to (5), $E, A_{0}$ and $c_{0}$ are Young's modulus, cross-sectional area, and longitudinal wave speed in incident and transmitted bars, respectively, and $A_{\mathrm{S}}$ and $L_{\mathrm{S}}$ are the initial cross-sectional area and length of the specimen, respectively. The true stress-strain relationship is determined from the engineering stress-strain relationship by assuming uniform and isochoric deformation conditions to prevail within the specimen during the deformation process.

Stress equilibrium within the samples is important for the interpretation of the experimental results. In a typical split Hopkinson pressure bar experiment (SHPB), as pointed out by Davies and Hunter (1963), the stress within the specimen reaches equilibrium state after approximately $\pi$ reverberations of the stress pulse within the specimen,

$t_{\text {equil }}=\frac{\pi L_{0}}{c_{\text {ice }}}$

where $L_{0}$ is length of specimen and $c_{i c e}$ is longitudinal elastic wave speed in ice. The average Young's modulus of ice is $10 \mathrm{GPa}$, and its density is approximately $897 \mathrm{~kg} / \mathrm{m}^{3}$ (Shazly et al., 2006a). Based on these values

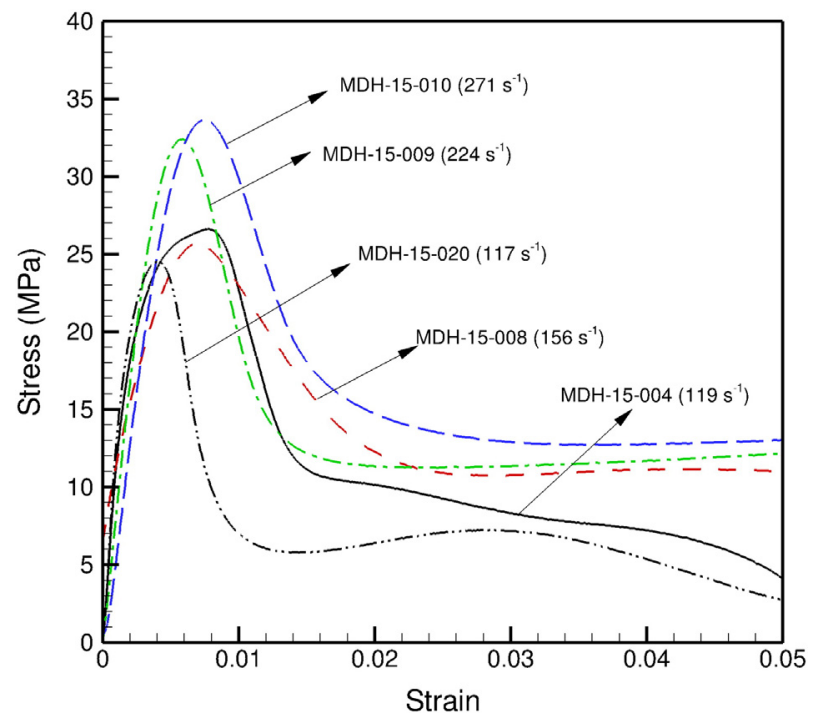

Fig. 7. Stress versus strain profiles for uniaxial compression on distilled water ice grown using steel inserts at a test temperature of $-15^{\circ} \mathrm{C}$.
Table 3

Experimental parameters for tests conducted at $-50^{\circ} \mathrm{C}$.

\begin{tabular}{llcll}
\hline Test name & $\begin{array}{l}\text { Test Temp } \\
\left({ }^{\circ} \mathrm{C}\right)\end{array}$ & $\begin{array}{l}\text { Thickness } \\
(\mathrm{mm})\end{array}$ & $\begin{array}{l}\text { Pulse shaper } \\
(\mathrm{mm})\end{array}$ & Type of insert \\
\hline MDH-50-010 & -52 & 4.7 & $5 \times 5 \times 0.25$ & Aluminum inserts \\
MDH-50-011 & -54 & 4.7 & $10 \times 10 \times 0.25$ & Aluminum inserts \\
MDH-50-013 & -54 & 4.7 & $12 \times 12 \times 0.25$ & Aluminum inserts \\
MDH-50-018 & -56 & 2.9 & $8 \times 8 \times 0.25$ & Aluminum inserts \\
MDH-50-019 & -56 & 3.0 & $10 \times 10 \times 0.25$ & Aluminum inserts \\
MDH-50-022 & -55 & 2.8 & $10 \times 10 \times 0.25$ & Aluminum inserts \\
MDH-50-023 & -55 & 2.9 & $10 \times 10 \times 0.25$ & Aluminum inserts \\
MDH-50-024 & -55 & 2.9 & $10 \times 10 \times 0.25$ & Aluminum inserts \\
MDH-50-025 & -55 & 28 & $10 \times 10 \times 0.25$ & Aluminum inserts \\
MDH-50-026 & -55 & 2.9 & $12 \times 12 \times 0.25$ & Aluminum inserts \\
\hline
\end{tabular}

the longitudinal elastic wave speed in ice can be approximated to be $3338 \mathrm{~m} / \mathrm{s}$. Using Eq. (4), the equilibrium time for a $3 \mathrm{~mm}$ thick ice specimen can be estimated to be $3 \mu \mathrm{s}$. This estimate provides a lower bound on time for attainment of peak stress in the ice specimens, which must be greater than that required to reach an equilibrium stress state. This condition can be facilitated using the pulse shaper technique to increase the rise time of the incident loading pulse. In the present study, annealed copper shims of various sizes were used as the pulse shapers for all of the experiments. The copper shims were placed on the impact end of the incident bar using a thin layer of vacuum grease. The size of the shim was determined by trial and error depending on the impact velocity and the test temperature (Frew et al., 2002). Firstly, a test was run with an arbitrary pulse shaper size. The transmitted signal was then used to optimize the size of pulse shaper by matching the slopes of the incident signals with that of the transmitted signal. Fig. 4 shows results of experiments conducted at a temperature of $-15^{\circ} \mathrm{C}$ to optimize the size of the pulse shaper at impact velocities of $5.6 \mathrm{~m} / \mathrm{s}$ and $6.9 \mathrm{~m} / \mathrm{s}$. In view of Fig. 4, it is clearly seen that the slopes of pulse shaper with size $3 \times 3 \times 0.25 \mathrm{~mm}$ were close to the slopes of transmitted signals at $5.6 \mathrm{~m} / \mathrm{s}$ and $6.9 \mathrm{~m} / \mathrm{s}$, respectively. Consequently annealed copper pulse shapers with size $3 \times 3 \times 0.25 \mathrm{~mm}$ were used at the test temperature of $-15{ }^{\circ} \mathrm{C}$ to achieve almost constant strain rate during the dynamic compression tests. In addition, pulse shapers were optimized for different test temperatures and impact velocities using a similar procedure and employed in the tests.

Since ice is a brittle, particularly in the ranges of temperatures and strain rates of interest in the present study, there is little time to establish a constant strain-rate before the samples fail (Shazly et al., 2006b; Shazly et al., 2009). As shown in Fig. 5 for two representative experiments of MDH-15-009 and MDH-15-20 at a temperature of $-15^{\circ} \mathrm{C}$, the strain rate increased with increasing time and a near constant strain rate was achieved near the peak stress using pulse shapers. The strain rate listed in the following tables represents an average value taken near the peak stress of the stress-strain curves. It is difficult to obtain constant strain rate over the entire duration of loading for ice samples.

Table 4

Experimental results for tests conducted at $-50{ }^{\circ} \mathrm{C}$.

\begin{tabular}{lclll}
\hline Test name & $\begin{array}{l}\text { Impact velocity } \\
(\mathrm{m} / \mathrm{s})\end{array}$ & $\begin{array}{l}\text { Strain rate } \\
\left(\mathrm{s}^{-1}\right)\end{array}$ & $\begin{array}{l}\text { Strain at peak stress } \\
\left(\times 10^{-3}\right)\end{array}$ & $\begin{array}{l}\text { Peak stress } \\
(\mathrm{MPa})\end{array}$ \\
\hline MDH-50-010 & 9.8 & 330 & 4.0 & 57.5 \\
MDH-50-011 & 10.5 & 378 & 3.5 & 65.0 \\
MDH-50-013 & 11.7 & 201 & 4.0 & 59.9 \\
MDH-50-018 & 9.4 & 254 & 2.6 & 52.0 \\
MDH-50-019 & 9.7 & 281 & 3.0 & 59.1 \\
MDH-50-022 & 10.7 & 384 & 3.7 & 67.1 \\
MDH-50-023 & 11.2 & 293 & 2.9 & 62.6 \\
MDH-50-024 & 11.0 & 503 & 4.9 & 69.0 \\
MDH-50-025 & 11.8 & 489 & 4.6 & 72.2 \\
MDH-50-026 & 14.1 & 420 & 2.8 & 59.9 \\
\hline
\end{tabular}




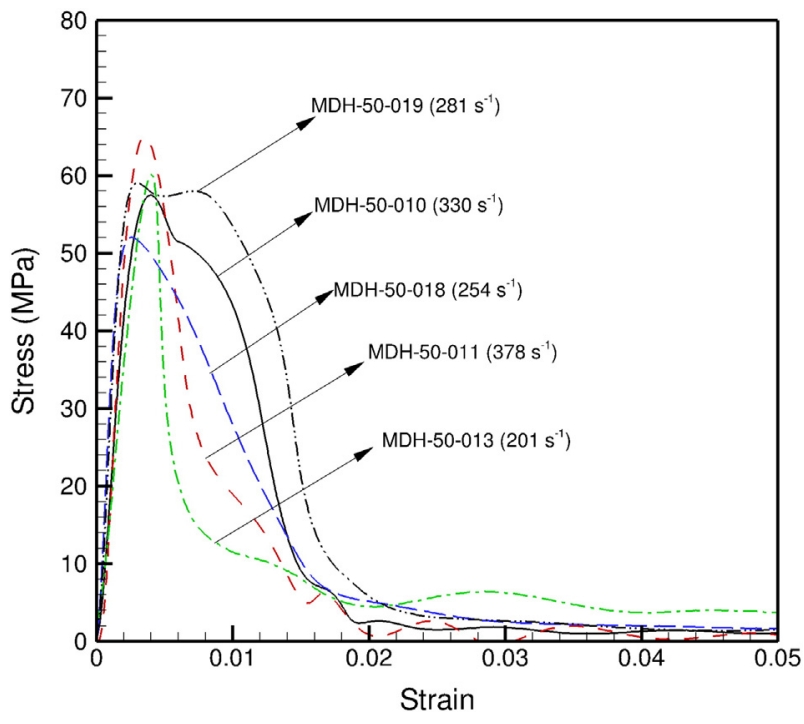

Fig. 8. Stress versus strain profiles for uniaxial compression on distilled water ice at relative low impact velocities at a test temperature of $-50{ }^{\circ} \mathrm{C}$.

Similar difficulties have been observed during high strain rate SHPB testing with other brittle materials such as ceramics (Sarva and Nemat-Nasser, 2001), Zr-based bulk metallic glass (Sunny et al., 2007, 2008, 2009) and rocks (Shan et al., 2000; Yuan et al., 2011).

\section{Experimental results}

In the present study dynamic uniaxial compression tests were conducted on ice samples at test temperatures of $-15{ }^{\circ} \mathrm{C},-50{ }^{\circ} \mathrm{C}$, $-80^{\circ} \mathrm{C},-125^{\circ} \mathrm{C},-150^{\circ} \mathrm{C}$ and $-173^{\circ} \mathrm{C}$. These experiments were conducted with either aluminum inserts having the same diameter as the incident and transmitted bars or with lower diameter impedance matched steel inserts. Since the sample diameter is smaller when using the steel inserts, hard ice samples with higher peak stress levels (at cryogenic test temperatures) can be investigated with high fidelity.

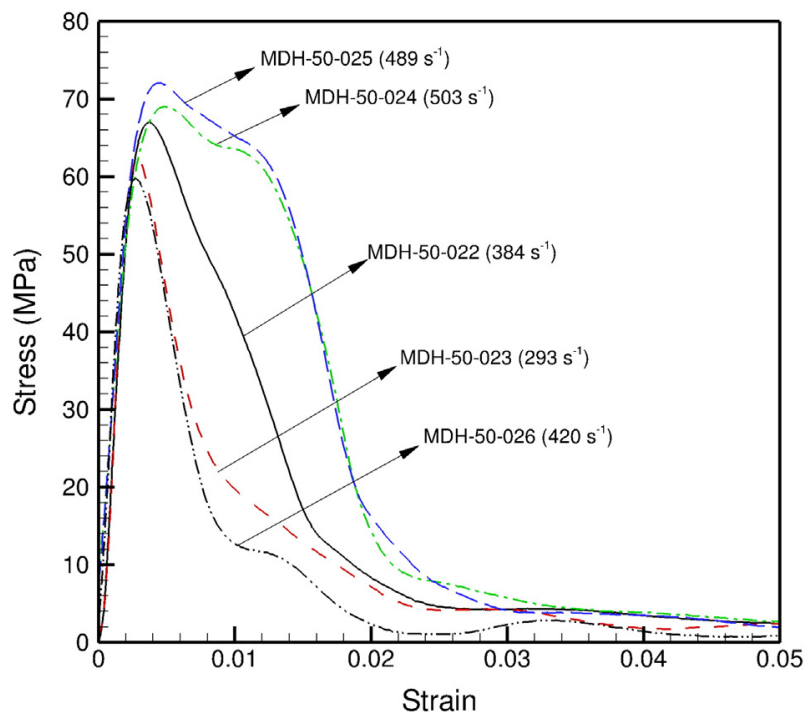

Fig. 9. Stress versus strain profiles for uniaxial compression on distilled water ice at relatively high impact velocities at a test temperature of $-50{ }^{\circ} \mathrm{C}$.
Table 5

Experimental parameters for tests conducted at $-80^{\circ} \mathrm{C}$.

\begin{tabular}{lllll}
\hline Test name & $\begin{array}{l}\text { Test Temp } \\
\left({ }^{\circ} \mathrm{C}\right)\end{array}$ & $\begin{array}{l}\text { Thickness } \\
(\mathrm{mm})\end{array}$ & $\begin{array}{l}\text { Pulse shaper } \\
(\mathrm{mm})\end{array}$ & Type of insert \\
\hline MDH-80-008 & -80 & 3.1 & $12 \times 12 \times 0.25$ & Aluminum inserts \\
MDH-80-009 & -82 & 3.2 & $12 \times 12 \times 0.25$ & Aluminum inserts \\
MDH-80-017 & -84 & 2.9 & $10 \times 10 \times 0.25$ & Aluminum inserts \\
MDH-80-018 & -87 & 3.0 & $10 \times 10 \times 0.25$ & Aluminum inserts \\
MDH-80-019 & -86 & 2.7 & $12 \times 12 \times 0.25$ & Aluminum inserts \\
MDH-80-020 & -82 & 2.1 & $12 \times 12 \times 0.25$ & Aluminum inserts \\
MDH-80-021 & -81 & 3.0 & $12 \times 12 \times 0.25$ & Aluminum inserts \\
MDH-80-024 & -80 & 2.8 & $10 \times 10 \times 0.25$ & Steel inserts \\
MDH-80-025 & -80 & 3.1 & $12 \times 12 \times 0.25$ & Steel inserts \\
\hline
\end{tabular}

\subsection{Test temperature of $-15^{\circ} \mathrm{C}$}

The first series of experiments was conducted at a test temperature of $-15^{\circ} \mathrm{C}$. Tables 1 and 2 summarize the experimental parameters and key results from these tests. The tables provides information on experiment number, test temperature, specimen thickness, pulse shaper size, type of inserts used to grow the ice samples, impact velocity, average strain rate, strain at peak stress, and the peak stress. For tests MDH15-021, MDH-15-022 and MDH-15-023, a pair of steel inserts with $11.23 \mathrm{~mm}$ diameter and $31.75 \mathrm{~mm}$ length were used to grow the ice samples. The diameter of the steel inserts were selected such that the acoustic impedance of the steel and aluminum inserts were nearly identical. Except for these tests, the ice samples were tested using aluminum inserts of $19.05 \mathrm{~mm}$ in diameter and $31.75 \mathrm{~mm}$ in length. The impact velocity of the striker varied from $4.9 \mathrm{~m} / \mathrm{s}$ to $7.0 \mathrm{~m} / \mathrm{s}$ for experiments conducted using the aluminum inserts and $1.9 \mathrm{~m} / \mathrm{s}$ to $3.0 \mathrm{~m} / \mathrm{s}$ for the steel inserts; the corresponding strain rates varied from 117 to $272 \mathrm{~s}^{-1}$. The peak stress in the ice samples were observed to vary from $24.5 \mathrm{MPa}$ to 33.6 MPa and the corresponding strains were in the range $3.5 \times 10^{-3}$ to $7.9 \times 10^{-3}$.

Figs. 6 and 7 show the stress versus strain profiles for tests conducted at $-15^{\circ} \mathrm{C}$. In all cases the ice samples were observed to fail by uniaxial crushing during the tests. The peak stress levels were observed to increase with increasing strain rates. In addition, the ice samples did not show a catastrophic drop in load carrying capacity after the attainment of the peak (failure) stress. In fact, after the attainment of peak stress, the strength of the samples is observed to drop to a plateau characterized by a long tail, indicating the existence of substantial residual strength of fragmented ice in its post peak-stress regime. The residual strength of ice is measured to be as high as $13 \mathrm{MPa}$ from tests MDHClean-008, MDH-Clean-009 and MDH-Clean-010, and can be best understood by considering the pulverized ice as an assemblage of wet highly fragmented granular material that is held together by ice melt created by grain-to-grain frictional sliding in the post peak-stress regime. The average strain at peak stress in the ice samples was estimated to be $5.9 \pm 2.3 \times 10^{-3}$.

Table 6

Experimental results for tests conducted at $-80^{\circ} \mathrm{C}$.

\begin{tabular}{lllll}
\hline Test name & $\begin{array}{l}\text { Impact velocity } \\
(\mathrm{m} / \mathrm{s})\end{array}$ & $\begin{array}{l}\text { Strain rate } \\
\left(\mathrm{s}^{-1}\right)\end{array}$ & $\begin{array}{l}\text { Strain at peak stress } \\
\left(\times 10^{-3}\right)\end{array}$ & $\begin{array}{l}\text { Peak stress } \\
(\mathrm{MPa})\end{array}$ \\
\hline MDH-80-008 & 11.5 & 447 & 4.6 & 79.2 \\
MDH-80-009 & 11.7 & 315 & 3.8 & 73.1 \\
MDH-80-017 & 11.2 & 407 & 4.1 & 83.9 \\
MDH-80-018 & 11.5 & 334 & 3.5 & 80.0 \\
MDH-80-019 & 11.1 & 376 & 4.0 & 79.1 \\
MDH-80-020 & 13.5 & 564 & 5.2 & 87.6 \\
MDH-80-021 & 15.2 & 400 & 4.0 & 89.1 \\
MDH-80-024 & 11.3 & 504 & 4.4 & 78.8 \\
MDH-80-025 & 7.8 & 321 & 3.5 & 66.4 \\
\hline
\end{tabular}




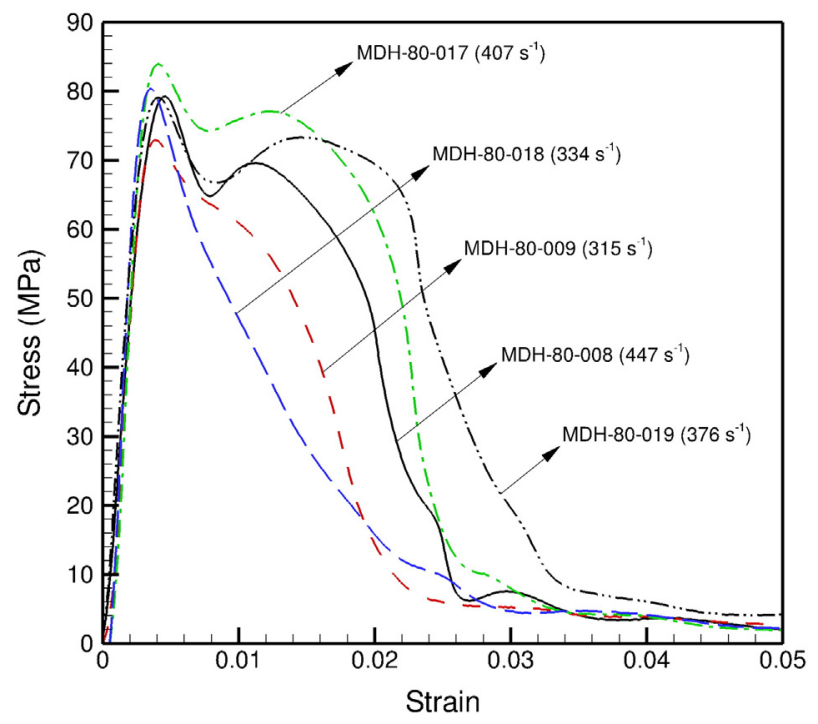

Fig. 10. Stress versus strain profiles for uniaxial compression on distilled water ice at relatively low impact velocities at a test temperature of $-80^{\circ} \mathrm{C}$.

\subsection{Test temperature of $-50{ }^{\circ} \mathrm{C}$}

Tables 3 and 4 summarize the experimental parameters and test results for the series of experiments conducted on distilled water ice at a test temperature of $-50{ }^{\circ} \mathrm{C}$. The ice samples utilized in this series of experiments were all grown between aluminum inserts. The impact velocity of the striker bar was varied from $9.4 \mathrm{~m} / \mathrm{s}$ to $14.1 \mathrm{~m} / \mathrm{s}$; the corresponding strain rates were 201 to $503 \mathrm{~s}^{-1}$. The peak stress levels in ice were observed to vary from 52 to $72.2 \mathrm{MPa}$, which are more than two times higher than that obtained at a temperature of $-15^{\circ} \mathrm{C}$. The strains at the peak stresses were $2.6 \times 10^{-3}$ to $4.9 \times 10^{-3}$, which are a little lower than the strains obtained from tests conducted at $-15{ }^{\circ} \mathrm{C}$. The average strain at peak stress was estimated to be $3.6 \pm$ $1.3 \times 10^{-3}$.

Figs. 8 and 9 show the stress versus strain profiles obtained for the tests conducted at a test temperature of $-50{ }^{\circ} \mathrm{C}$. In all tests, the peak stress levels were observed to increase with increasing strain rates and the specimens were observed to fail by uniaxial crushing. In

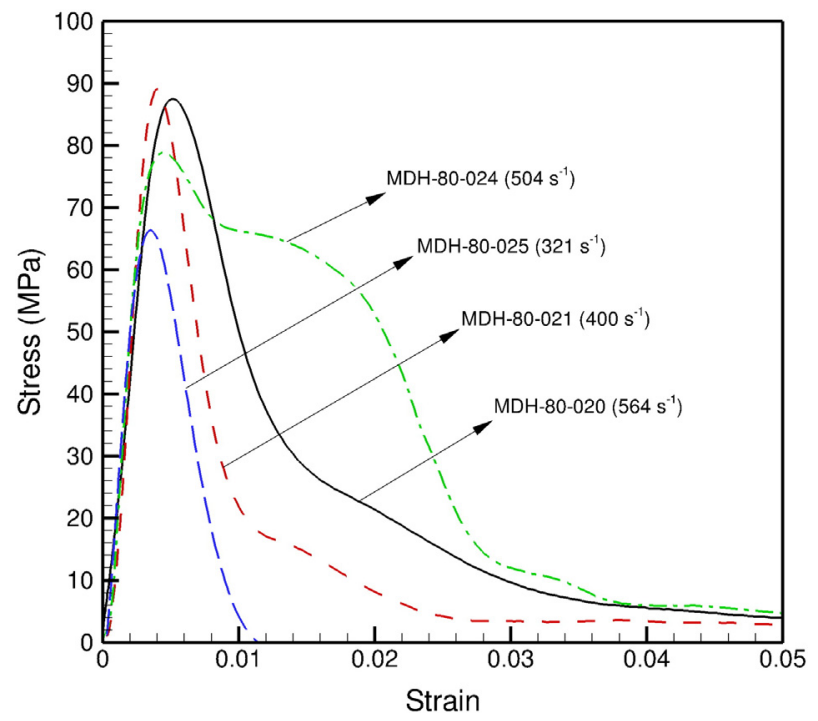

Fig. 11. Stress versus strain profiles for uniaxial compression on distilled water ice at relatively high impact velocities at a test temperature of $-80^{\circ} \mathrm{C}$.
Table 7

Experimental parameters for tests conducted at $-125^{\circ} \mathrm{C}$.

\begin{tabular}{lllll}
\hline Test name & $\begin{array}{l}\text { Test Temp } \\
\left({ }^{\circ} \mathrm{C}\right)\end{array}$ & $\begin{array}{l}\text { Thickness } \\
(\mathrm{mm})\end{array}$ & $\begin{array}{l}\text { Pulse shaper } \\
(\mathrm{mm})\end{array}$ & Type of insert \\
\hline MDH-125-002 & -126 & 3.3 & $10 \times 10 \times 0.25$ & Aluminum inserts \\
MDH-125-003 & -122 & 2.9 & $12 \times 12 \times 0.25$ & Aluminum inserts \\
MDH-125-004 & -125 & 2.9 & $12 \times 12 \times 0.25$ & Aluminum inserts \\
MDH-125-005 & -120 & 2.9 & $12 \times 12 \times 0.25$ & Aluminum inserts \\
MDH-125-006 & -122 & 2.9 & $12 \times 12 \times 0.25$ & Aluminum inserts \\
MDH-125-007 & -125 & 2.9 & $12 \times 12 \times 0.25$ & Aluminum inserts \\
MDH-125-008 & -124 & 2.9 & $12 \times 12 \times 0.25$ & Aluminum inserts \\
MDH-125-009 & -124 & 2.9 & $12 \times 12 \times 0.25$ & Aluminum inserts \\
MDH-125-010 & -123 & 3.1 & $12 \times 12 \times 0.25$ & Steel inserts \\
MDH-125-011 & -125 & 3.0 & $12 \times 12 \times 0.25$ & Steel inserts \\
MDH-125-012 & -125 & 3.1 & $12 \times 12 \times 0.25$ & Steel inserts \\
MDH-125-013 & -124 & 3.2 & $12 \times 12 \times 0.25$ & Steel inserts \\
MDH-125-015 & -125 & 3.0 & $12 \times 12 \times 0.25$ & Steel inserts \\
\hline
\end{tabular}

addition, the dynamic stress versus strain profiles indicate that a residual strength of approximately $5 \mathrm{MPa}$ is maintained in the post peak stress (failure) regime. Moreover, for tests MDH-50-019, MDH-50-024 and MDH-50-025, the ice samples show the presence of a shoulder at failure (near the peak stress), which is followed by a catastrophic drop in dynamic strength with further accumulation of inelastic strain. The presence of the shoulder is an indication that the failure/fragmentation in the ice samples is preceded by fracture into relatively large ice fragments sandwiched between the aluminum inserts, which can carry substantial fraction of the peak compressive load before extensive fragmentation can occur. It is interesting to note that this double peak is absent in the experiments conducted at $-15^{\circ} \mathrm{C}$, where the ice samples are soft enough such that they deform essentially in a ductile fashion during dynamic compression.

\subsection{Test temperature of $-80^{\circ} \mathrm{C}$}

Tables 5 and 6 summarize the experimental parameters and results for tests conducted at a temperature of $-80^{\circ} \mathrm{C}$. Aluminum inserts were employed in all tests except for tests MDH-80-024 and MDH-80-025, where the samples were sandwiched between steel inserts. The impact velocity of the striker bar was varied from $\mathrm{m} / \mathrm{s} 7.8$ to $15.2 \mathrm{~m} / \mathrm{s}$, and the corresponding strain rates were in the range 315 to $564 \mathrm{~s}^{-1}$. The peak stress levels attained in ice were observed to vary from 66.4 MPa to 89.1 MPa, which are higher than those obtained at the test temperature of $-50{ }^{\circ} \mathrm{C}$. The strains at the peak stresses were $3.5 \times 10^{-3}$ to $5.2 \times 10^{-3}$, which are almost at the same level as the tests conducted at $-50{ }^{\circ} \mathrm{C}$. The average strain at peak stress for this series of tests was estimated to be $4.1 \pm 1.1 \times 10^{-3}$.

Table 8

Experimental results for tests conducted at $-125^{\circ} \mathrm{C}$.

\begin{tabular}{lllll}
\hline Test name & $\begin{array}{l}\text { Impact velocity } \\
(\mathrm{m} / \mathrm{s})\end{array}$ & $\begin{array}{l}\text { Strain rate } \\
\left(\mathrm{s}^{-1}\right)\end{array}$ & $\begin{array}{l}\text { Strain at peak stress } \\
\left(\times 10^{-3}\right)\end{array}$ & $\begin{array}{l}\text { Peak stress } \\
(\mathrm{MPa})\end{array}$ \\
\hline MDH-125-002 & 18.5 & 463 & 3.6 & 107.9 \\
MDH-125-003 & 14.2 & 540 & 4.2 & 101.8 \\
MDH-125-004 & 13.9 & 364 & 3.6 & 105.0 \\
MDH-125-005 & 15.5 & 523 & 5.1 & 118.4 \\
MDH-125-006 & 14.5 & 407 & 4.1 & 107.6 \\
MDH-125-007 & 16.6 & 498 & 6.1 & 112.0 \\
MDH-125-008 & 16.9 & 577 & 5.5 & 112.1 \\
MDH-125-009 & 17.8 & 445 & 4.1 & 113.4 \\
MDH-125-010 & 17.7 & 720 & 5.5 & 110.3 \\
MDH-125-011 & 8.9 & 534 & 6.0 & 107.4 \\
MDH-125-012 & 8.7 & 451 & 5.8 & 104.4 \\
MDH-125-013 & 11.2 & 487 & 4.9 & 94.7 \\
MDH-125-015 & 11.4 & 447 & 3.9 & 93.0 \\
\hline
\end{tabular}




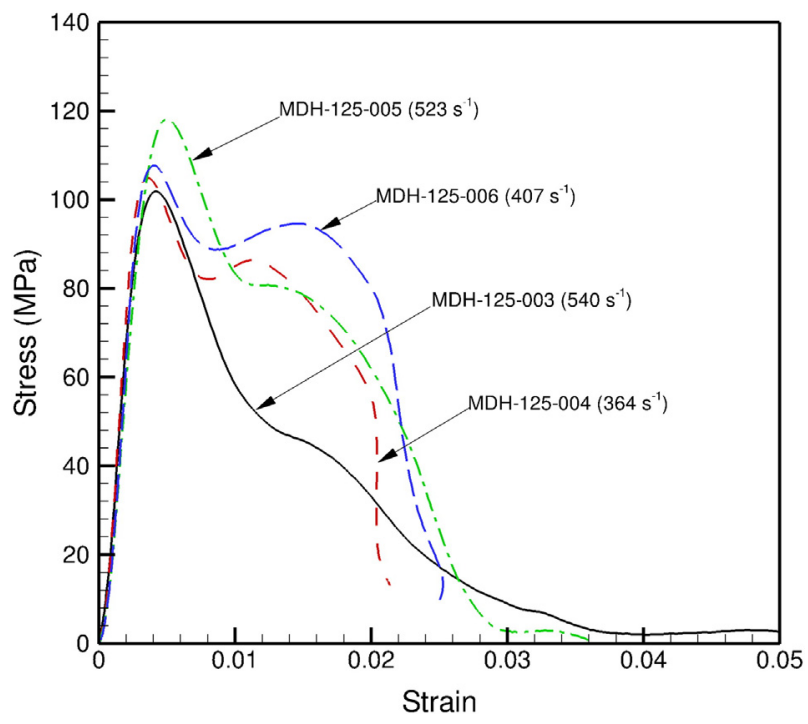

Fig. 12. Stress versus strain profiles for uniaxial compression on distilled water ice grown using aluminum inserts at relatively low impact velocities at a test temperature of $-125^{\circ} \mathrm{C}$.

Figs. 10 and 11 show the stress versus strain curves for tests conducted at $-80{ }^{\circ} \mathrm{C}$. All specimens were observed to fail by axial splitting/fracture followed by extensive fragmentation/pulverization during the tests. From the Figures we can observe that the peak stresses increase with increasing strain rates, and in the post peak-stress regime ice shows a finite non-zero residual strength of approximate $4 \mathrm{MPa}$. Moreover, it is interesting to note the presence of the double peak at failure (near the peak stress for tests $\mathrm{MDH}-80-08, \mathrm{MDH}-80-017$ and MDH-80-019), which is followed by a catastrophic drop in dynamic strength with the accumulation of inelastic strain. The formation of the double peak is understood to be due to the fracture of "harder" ice (promoted by the lower test temperature) into large fragments that are reloaded before complete pulverization of ice can take place.

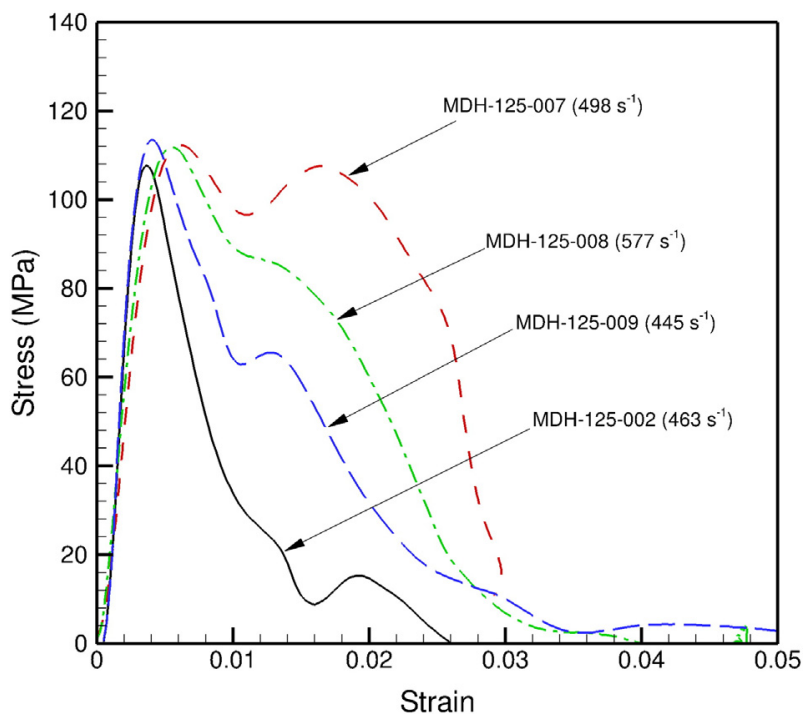

Fig. 13. Stress versus strain profiles for uniaxial compression on distilled water ice grown using aluminum inserts at relatively high impact velocities at a test temperature of $-125^{\circ} \mathrm{C}$.

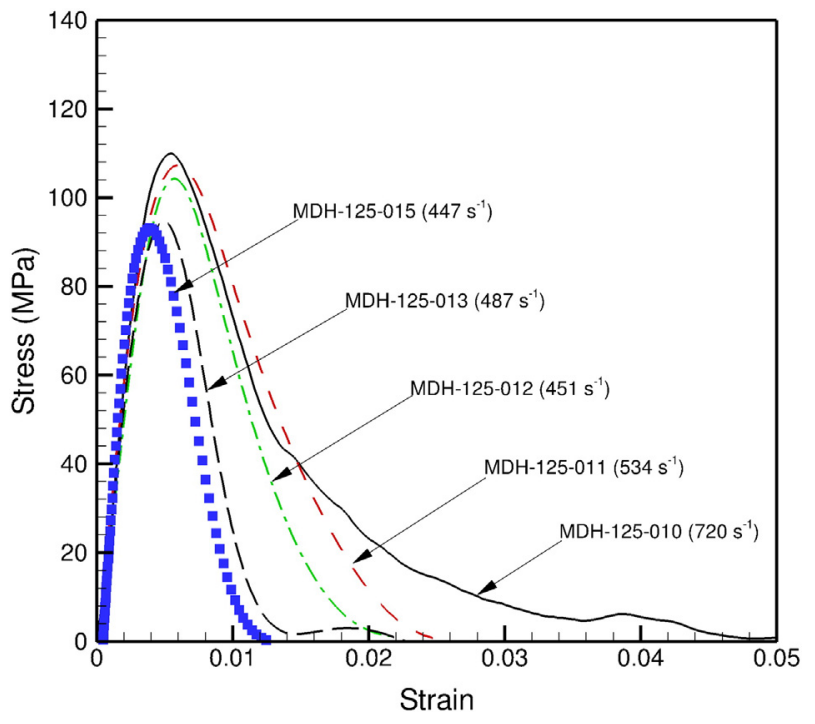

Fig. 14. Stress versus strain profiles for uniaxial compression on distilled water ice grown using steel inserts at a test temperature of $-125^{\circ} \mathrm{C}$.

\subsection{Test temperature of $-125^{\circ} \mathrm{C}$}

Tables 7 and 8 summarize the experimental parameters and results for the tests conducted at $-125{ }^{\circ} \mathrm{C}$. For tests MDH-125-002 to MDH125-009 aluminum inserts were utilized while for tests MDH-125-010 to $\mathrm{MDH}-125-015$ steel inserts were used in conducting the experiments. As also discussed earlier, the use of the steel inserts allow higher stresses to be used during the uniaxial compression loading. The impact velocities of the striker were varied from $8.7 \mathrm{~m} / \mathrm{s}$ to $18.5 \mathrm{~m} / \mathrm{s}$; the corresponding strain rates obtained in the ice samples varied from 364 to $720 \mathrm{~s}^{-1}$. The peak stresses in ice were measured to be in the range of 93.0 MPa to 118.4 MPa, which are much higher than those obtained at $-80^{\circ} \mathrm{C}$. The corresponding strains at peak stress were measured to be between $3.6 \times 10^{-3}$ and $6.1 \times 10^{-3}$, which are almost at the same level as the tests at $-50{ }^{\circ} \mathrm{C}$ and $-80^{\circ} \mathrm{C}$. The corresponding average strain at the peak stress was estimated to be $4.8 \pm 1.3 \times 10^{-3}$.

Figs. 12 to 14 show the stress versus strain profiles for the tests conducted at a temperature of $-125^{\circ} \mathrm{C}$. All specimens were observed to fail by axial splitting/fracture at the peak stress level followed by extensive fragmentation/pulverization with accumulation of inelastic strain. It is interesting to note that the sensitivity of peak stress to strain rate

Table 9

Experimental parameters for tests conducted at $-150{ }^{\circ} \mathrm{C}$.

\begin{tabular}{|c|c|c|c|c|}
\hline Test name & $\begin{array}{l}\text { Test Temp } \\
\left({ }^{\circ} \mathrm{C}\right)\end{array}$ & $\begin{array}{l}\text { Thickness } \\
(\mathrm{mm})\end{array}$ & $\begin{array}{l}\text { Pulse shaper } \\
(\mathrm{mm})\end{array}$ & Type of insert \\
\hline MDH-150-004 & -153 & 3.2 & $12 \times 12 \times 0.25$ & Steel insert \\
\hline MDH-150-005 & -151 & 3.1 & $12 \times 12 \times 0.25$ & Steel insert \\
\hline MDH-150-007 & -150 & 3.2 & $12 \times 12 \times 0.25$ & Steel insert \\
\hline MDH-150-009 & -150 & 3.2 & $12 \times 12 \times 0.25$ & Steel insert \\
\hline MDH-150-010 & -152 & 3.1 & $12 \times 12 \times 0.25$ & Steel insert \\
\hline MDH-150-011 & -155 & 3.2 & $12 \times 12 \times 0.25$ & Aluminum insert \\
\hline MDH-150-013 & -151 & 3.1 & $12 \times 12 \times 0.25$ & Aluminum insert \\
\hline MDH-150-014 & -151 & 3.1 & $12 \times 12 \times 0.25$ & Aluminum insert \\
\hline MDH-150-015 & -147 & 3.2 & $12 \times 12 \times 0.25$ & Aluminum insert \\
\hline MDH-150-016 & -155 & 3.1 & $12 \times 12 \times 0.25$ & Aluminum insert \\
\hline MDH-150-017 & -152 & 3.2 & $12 \times 12 \times 0.25$ & Aluminum insert \\
\hline MDH-150-018 & -152 & 3.1 & $12 \times 12 \times 0.25$ & Aluminum insert \\
\hline MDH-150-020 & -151 & 3.1 & $12 \times 12 \times 0.25$ & Steel insert \\
\hline MDH-150-021 & -150 & 3.2 & $12 \times 12 \times 0.25$ & Steel insert \\
\hline MDH-150-022 & -151 & 3.0 & $12 \times 12 \times 0.25$ & Steel insert \\
\hline MDH-150-023 & -150 & 3.0 & $12 \times 12 \times 0.25$ & Steel insert \\
\hline MDH-150-024 & -150 & 3.1 & $12 \times 12 \times 0.25$ & Steel insert \\
\hline
\end{tabular}


Table 10

Experimental results for tests conducted at $-150{ }^{\circ} \mathrm{C}$.

\begin{tabular}{lcllc}
\hline Test name & $\begin{array}{l}\text { Impact velocity } \\
(\mathrm{m} / \mathrm{s})\end{array}$ & $\begin{array}{l}\text { Strain rate } \\
\left(\mathrm{s}^{-1}\right)\end{array}$ & $\begin{array}{l}\text { Strain at peak stress } \\
\left(\times 10^{-3}\right)\end{array}$ & $\begin{array}{c}\text { Peak stress } \\
(\mathrm{MPa})\end{array}$ \\
\hline MDH-150-004 & 9.4 & 413 & 3.6 & 99.5 \\
MDH-150-005 & 9.2 & 630 & 4.9 & 116.8 \\
MDH-150-007 & 9.8 & 498 & 4.3 & 108.7 \\
MDH-150-009 & 10.7 & 453 & 3.5 & 101.5 \\
MDH-150-010 & 11.5 & 873 & 5.1 & 98.8 \\
MDH-150-011 & 18.2 & 688 & 5.3 & 100.1 \\
MDH-150-013 & 18.9 & 1308 & 6.2 & 93.4 \\
MDH-150-014 & 18.8 & 1073 & 5.6 & 98.3 \\
MDH-150-015 & 18.3 & 805 & 3.9 & 86.4 \\
MDH-150-016 & 21.4 & 678 & 4.7 & 106.3 \\
MDH-150-017 & 22.7 & 921 & 5.5 & 107.2 \\
MDH-150-018 & 24.0 & 1057 & 6.1 & 104.4 \\
MDH-150-020 & 9.2 & 388 & 3.4 & 110.3 \\
MDH-150-021 & 9.8 & 359 & 3.3 & 95.6 \\
MDH-150-022 & 13.2 & 574 & 4.2 & 89.3 \\
MDH-150-023 & 11.1 & 457 & 3.7 & 101.1 \\
MDH-150-024 & 11.3 & 471 & 4.8 & \\
\hline
\end{tabular}

decreases as the test temperature is reduced to $-125^{\circ} \mathrm{C}$ when compared to the higher test temperatures. Moreover, the majority of the ice samples tested using aluminum inserts show a double peak (as seen from Figs. 12 and 13), while the double peak is virtually absent in the case of ice samples tested using the steel inserts (Fig. 14). These differences in the observed dynamic behavior (double peak for aluminum inserts versus single peak for steel inserts) can be attributed to essentially geometrical effects where the ice samples following axial splitting/fracture under dynamic compression are trapped between the larger diameter aluminum inserts when compared to the smaller diameter steel inserts, and are thus reloaded to give the double peak.

\subsection{Test temperature of $-150{ }^{\circ} \mathrm{C}$}

The experimental parameters and experimental results for tests conducted at $-150{ }^{\circ} \mathrm{C}$ are summarized in Tables 9 and 10 . In this series of experiments both impedance matched aluminum and steel inserts were utilized to conduct the experiments. The smaller diameter steel inserts were used to provide higher stress levels when compared to the aluminum inserts for the same impact velocity range. The impact

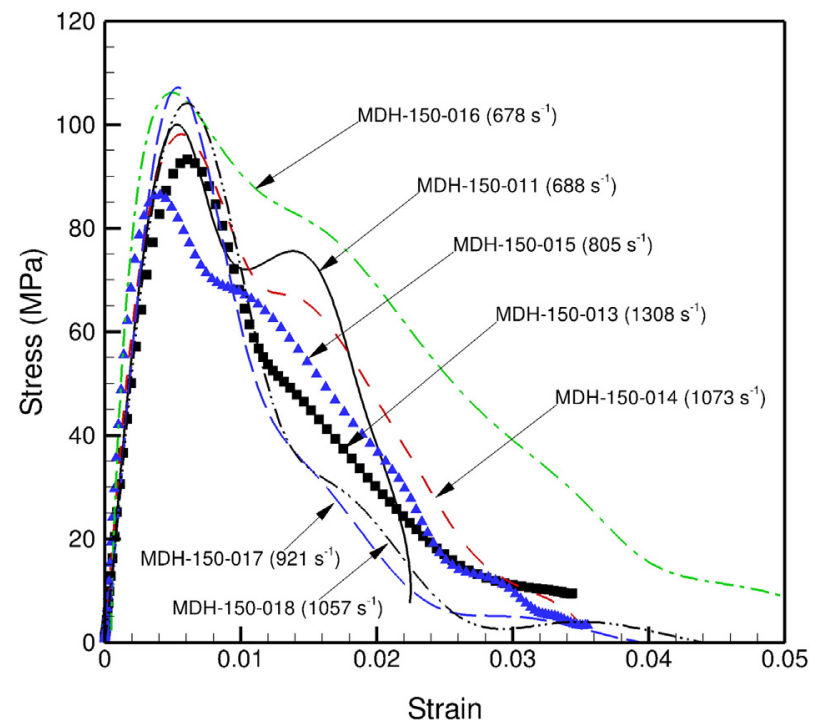

Fig. 15. Stress versus strain profiles for uniaxial compression on distilled water ice grown using aluminum inserts at a test temperature of $-150{ }^{\circ} \mathrm{C}$.

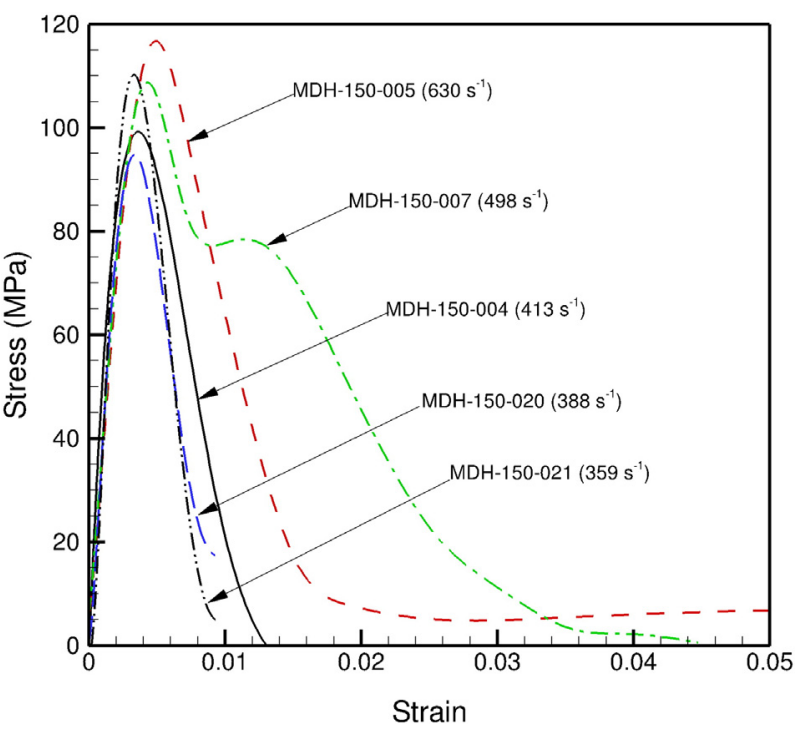

Fig. 16. Stress versus strain profiles for uniaxial compression on distilled water ice grown using steel inserts at relatively low impact velocities at a test temperature of $-150^{\circ} \mathrm{C}$.

velocities of the striker were varied from $9.2 \mathrm{~m} / \mathrm{s}$ to $24 \mathrm{~m} / \mathrm{s}$; the corresponding strain rates in the ice samples were estimated to vary between 413 and $1308 \mathrm{~s}^{-1}$. The peak stresses obtained in the ice samples ranged from 86.4 MPa to 116.8 MPa, which are almost at the same level as those obtained at $-125{ }^{\circ} \mathrm{C}$. The strains corresponding to the peak stresses were measured to be in the range from $3.3 \times 10^{-3}$ to $6.2 \times 10^{-3}$, which are similar to the strains obtained for $-50{ }^{\circ} \mathrm{C},-80{ }^{\circ} \mathrm{C}$ and $-125^{\circ} \mathrm{C}$. The average strain at peak stress for this series of tests was estimated to be $4.6 \pm 1.6 \times 10^{-3}$.

Figs. 15 to 17 show the stress versus strain profiles for tests conducted at $-150^{\circ} \mathrm{C}$. Nearly all the ice samples are observed to fracture at the peak stress and undergo extensive fragmentation during the test. Also, it is interesting to note that the sensitivity of peak stress to strain rate is observed to be considerably lower at $-150{ }^{\circ} \mathrm{C}$ when compared to tests at higher temperatures. Also, the double peak observed in the stress versus strain profiles at test temperatures of $-80{ }^{\circ} \mathrm{C}$ and $-125{ }^{\circ} \mathrm{C}$ is less prominent at $-150{ }^{\circ} \mathrm{C}$ and the re-loading behavior

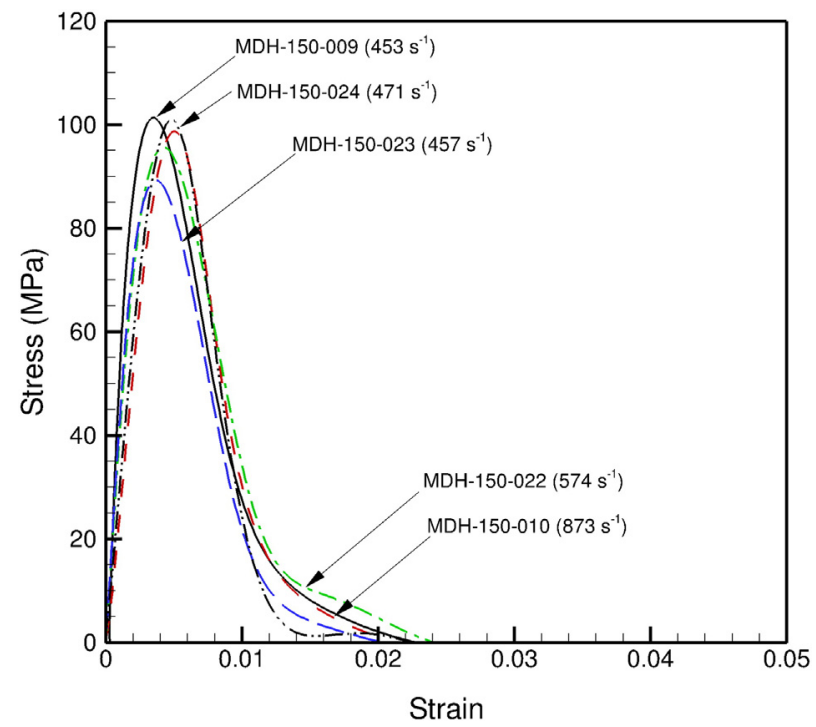

Fig. 17. Stress versus strain profiles for uniaxial compression on distilled water ice grown using steel inserts at relatively high impact velocities at a test temperature of $-150{ }^{\circ} \mathrm{C}$. 
Table 11

Experimental parameters for tests conducted at $-173^{\circ} \mathrm{C}$.

\begin{tabular}{lllll}
\hline Test name & $\begin{array}{l}\text { Test Temp } \\
\left({ }^{\circ} \mathrm{C}\right)\end{array}$ & $\begin{array}{l}\text { Thickness } \\
(\mathrm{mm})\end{array}$ & $\begin{array}{l}\text { Pulse shaper } \\
(\mathrm{mm})\end{array}$ & Type of insert \\
\hline MDH-173-002 & -170 & 3.1 & $12 \times 12 \times 0.25$ & Steel inserts \\
MDH-173-003 & -169 & 3.2 & $12 \times 12 \times 0.25$ & Steel inserts \\
MDH-173-004 & -173 & 3.0 & $12 \times 12 \times 0.25$ & Steel inserts \\
MDH-173-005 & -170 & 3.0 & $12 \times 12 \times 0.25$ & Steel inserts \\
MDH-173-006 & -173 & 3.1 & $12 \times 12 \times 0.25$ & Steel inserts \\
MDH-173-007 & -173 & 3.2 & $12 \times 12 \times 0.25$ & Steel inserts \\
MDH-173-009 & -173 & 3.2 & $12 \times 12 \times 0.25$ & Steel inserts \\
MDH-173-010 & -170 & 3.1 & $12 \times 12 \times 0.25$ & Steel inserts \\
MDH-173-013 & -173 & 3.1 & $12 \times 12 \times 0.25$ & Steel inserts \\
MDH-173-014 & -173 & 3.1 & $12 \times 12 \times 0.25$ & Steel inserts \\
MDH-173-016 & -173 & 3.1 & $12 \times 12 \times 0.25$ & Steel inserts \\
\hline
\end{tabular}

after the attainment of the peak stress is observed only in a few tests conducted using the larger diameter aluminum inserts. Again, this behavior can be attributed to a combination of the mode of ice fracture and geometrical effects arising because of the two different insert diameters utilized in the tests. Since the much harder ice samples at $-150^{\circ} \mathrm{C}$ undergo extensive fragmentation after the attainment of the peak stress in these tests, the probability of the ice fragments to be trapped between the loading faces of either the larger diameter aluminum inserts or the smaller diameter steel inserts is much lower when compared to tests conducted at higher temperatures, and hence the absence of the double peak.

\subsection{Test temperature of $-173{ }^{\circ} \mathrm{C}$}

Finally, the uniaxial compression behavior of ice at a test temperature of $-173{ }^{\circ} \mathrm{C}$ and at high loading rates was investigated. Tables 11 and 12 summarize the experimental parameters and experimental results obtained in the tests. Steel inserts were used in all tests in this series of experiments. The impact velocity of the striker bar was varied from $8.76 \mathrm{~m} / \mathrm{s}$ to $13.95 \mathrm{~m} / \mathrm{s}$; the corresponding strain rates were in the range 417 to $1201 \mathrm{~s}^{-1}$. The peak stresses in the ice samples were observed to vary from 101.4 MPa to 127.3 MPa, which are a little higher than those obtained at test temperatures of $-125{ }^{\circ} \mathrm{C}$ and $-150{ }^{\circ} \mathrm{C}$. The strains at peak stress were measured to be between $4.2 \times 10^{-3}$ to $7.3 \times 10^{-3}$, which are slightly higher when compared to the tests at the temperatures of $-50{ }^{\circ} \mathrm{C},-80^{\circ} \mathrm{C},-125^{\circ} \mathrm{C}$ and $-150{ }^{\circ} \mathrm{C}$. The average strain at peak stress for this series of experiments was estimated to be $5.3 \pm 2.0 \times 10^{-3}$.

Figs. 18 and 19 show the stress versus strain profiles for the tests conducted at a test temperature of $-173^{\circ} \mathrm{C}$. In all cases steel inserts were used in the experiments and the ice samples were observed to fail by fracture followed by extensive fragmentation into very fine ice particulates during the tests. As also observed for the tests at $-125^{\circ} \mathrm{C}$

Table 12

Experimental results for tests conducted at $-173^{\circ} \mathrm{C}$.

\begin{tabular}{lllll}
\hline Test name & $\begin{array}{l}\text { Impact velocity } \\
(\mathrm{m} / \mathrm{s})\end{array}$ & $\begin{array}{l}\text { Strain rate } \\
\left(\mathrm{s}^{-1}\right)\end{array}$ & $\begin{array}{l}\text { Strain at peak stress } \\
\left(\times 10^{-3}\right)\end{array}$ & $\begin{array}{l}\text { Peak stress } \\
(\mathrm{MPa})\end{array}$ \\
\hline MDH-173-002 & \multicolumn{1}{|c}{11.2} & 440 & 4.6 & 127.3 \\
$\mathrm{MDH}-173-003$ & 14.0 & 1201 & 6.2 & 121.0 \\
$\mathrm{MDH}-173-004$ & 9.8 & 733 & 7.3 & 119.0 \\
$\mathrm{MDH}-173-005$ & 11.7 & 510 & 4.4 & 115.8 \\
$\mathrm{MDH}-173-006$ & 8.8 & 786 & 5.6 & 111.9 \\
$\mathrm{MDH}-173-007$ & 10.0 & 442 & 5.3 & 104.3 \\
$\mathrm{MDH}-173-009$ & 10.6 & 502 & 4.3 & 101.4 \\
$\mathrm{MDH}-173-010$ & 10.2 & 536 & 5.4 & 104.3 \\
MDH-173-013 & 11.1 & 417 & 4.2 & 116.8 \\
$\mathrm{MDH}-173-014$ & 10.2 & 528 & 5.6 & 112.4 \\
MDH-173-016 & 12.9 & 657 & 5.0 & \\
\hline
\end{tabular}

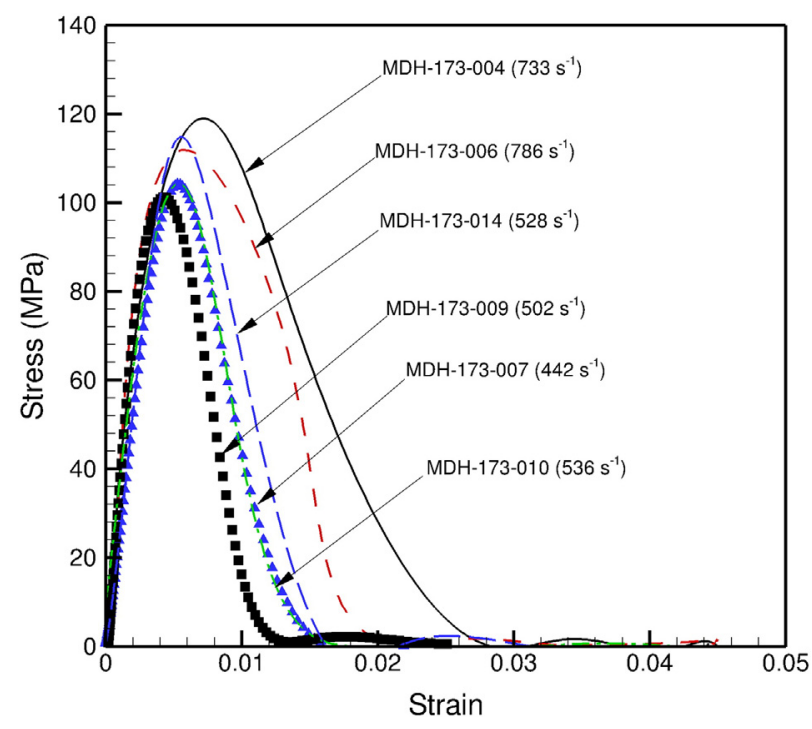

Fig. 18. Stress versus strain profiles for uniaxial compression on distilled water ice grown using steel inserts at relatively low impact velocities at a test temperature of $-173^{\circ} \mathrm{C}$.

and $-150{ }^{\circ} \mathrm{C}$, the sensitivity of peak stress to the strain rate is lower when compared to tests in the temperature range from $-15{ }^{\circ} \mathrm{C}$ to $-125^{\circ} \mathrm{C}$. However, the peak strength of the ice samples at the test temperature of $-173^{\circ} \mathrm{C}$ is nearly at the same level (range) as obtained from tests conducted at $-125^{\circ} \mathrm{C}$ and $-150{ }^{\circ} \mathrm{C}$. Moreover, except for Test MDH-173-002, none of the experiments exhibit a double peak in their stress versus strain profiles. Again, this behavior can be attributed to the fine scale pulverization of the highly brittle ice samples during the dynamic compression loading and the relatively smaller diameter of the steel inserts which inhibit trapping and subsequent reloading of the ice fragments in between the loading faces of the inserts.

\section{Results and discussion}

In the present paper, the dynamic uniaxial compression behavior of distilled water ice (polycrystalline ice Ih) is investigated at cryogenic temperatures using a modified split Hopkinson pressure bar. Typical stress versus strain profiles for ice obtained at test temperatures of

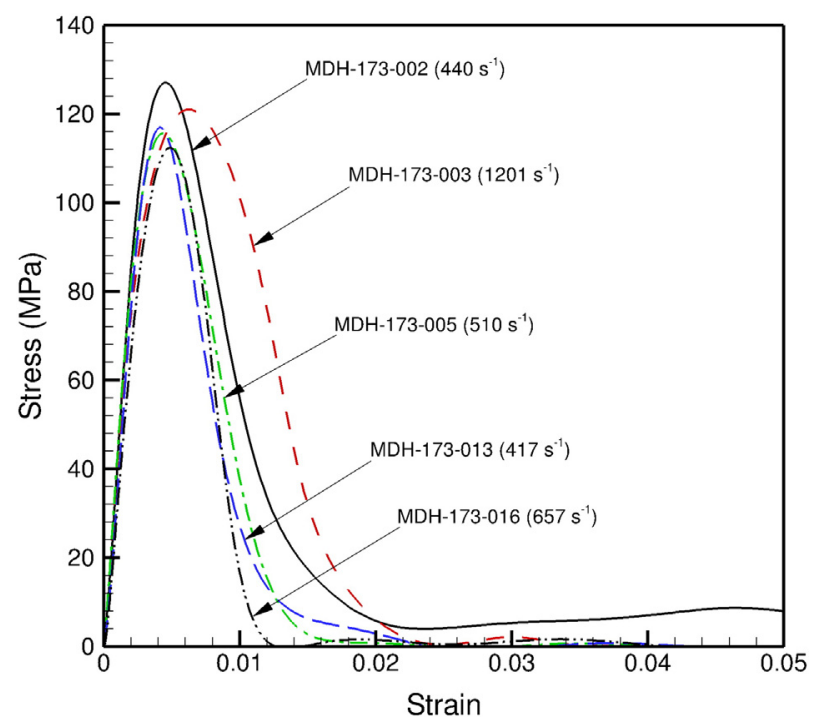

Fig. 19. Stress versus strain profiles for uniaxial compression on distilled water ice grown using steel inserts at relatively high impact velocities at a test temperature of $-173^{\circ} \mathrm{C}$. 

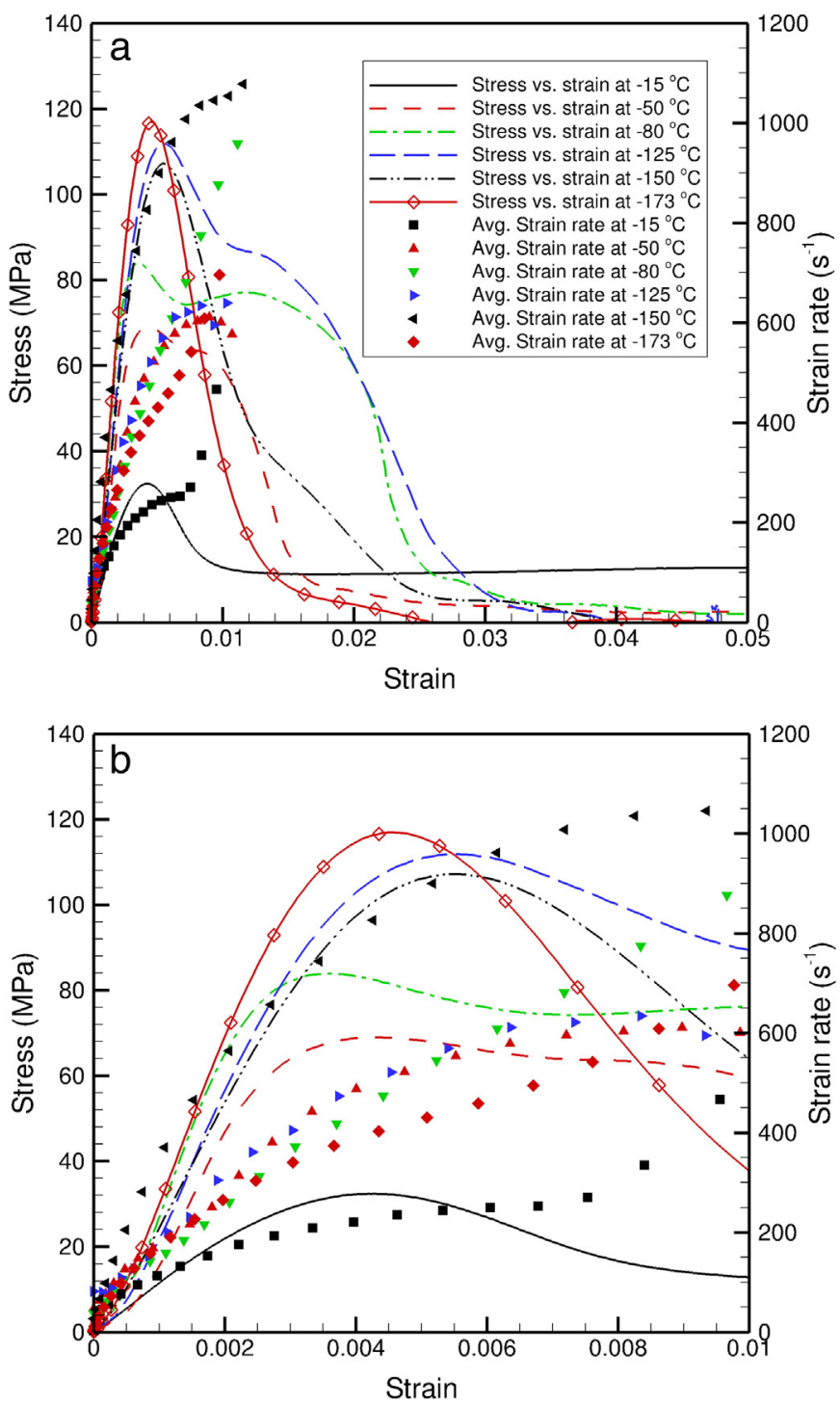

Fig. 20. (a) Typical stress versus strain profiles for uniaxial compression of distilled water ice obtained at test temperatures of $-15^{\circ} \mathrm{C},-50{ }^{\circ} \mathrm{C},-80{ }^{\circ} \mathrm{C},-125^{\circ} \mathrm{C},-150{ }^{\circ} \mathrm{C}$ and $-173^{\circ} \mathrm{C}$; (b) an expanded view of the information shown in Fig. 20a in the strain range from 0 to 0.01 .

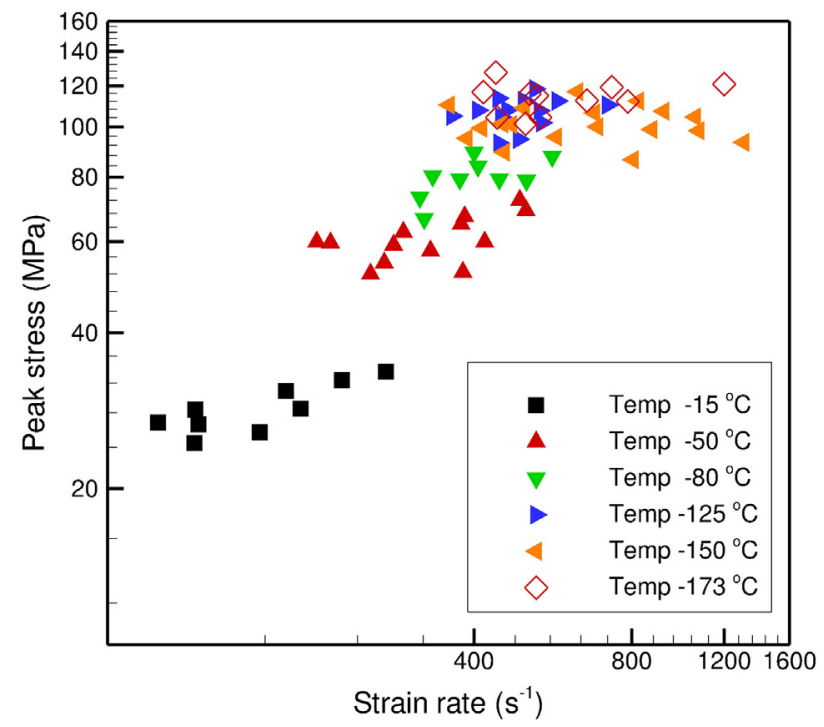

Fig. 22. Logarithmic of peak stress versus logarithm of strain-rate for dynamic uniaxial compression on distilled water ice at test temperatures of $-15{ }^{\circ} \mathrm{C},-50{ }^{\circ} \mathrm{C},-80{ }^{\circ} \mathrm{C}$, $-125{ }^{\circ} \mathrm{C},-150{ }^{\circ} \mathrm{C}$ and $-173{ }^{\circ} \mathrm{C}$

$-15^{\circ} \mathrm{C},-50^{\circ} \mathrm{C},-80^{\circ} \mathrm{C},-125^{\circ} \mathrm{C},-150^{\circ} \mathrm{C}$ and $-173^{\circ} \mathrm{C}$, are shown in Fig. 20a. Fig. 20b shows the same information as in Fig. 20a but in the strain range from 0 to 0.01 . It is interesting to note that under dynamic compression the peak stress increases from $32 \mathrm{MPa}$ to $112 \mathrm{MPa}$ as the test temperatures are decreased from $-15{ }^{\circ} \mathrm{C}$ to $-125{ }^{\circ} \mathrm{C}$ and then remains nearly constant in the range $112-120 \mathrm{MPa}$ as the test temperatures are decreased from $-125{ }^{\circ} \mathrm{C}$ to $-173{ }^{\circ} \mathrm{C}$. In addition, the curvature of the stress versus strain profiles near the peak stress at test temperatures of $-50{ }^{\circ} \mathrm{C},-80{ }^{\circ} \mathrm{C},-125{ }^{\circ} \mathrm{C},-150{ }^{\circ} \mathrm{C}$ and $-173^{\circ} \mathrm{C}$ are observed to be relatively sharp when compared to the curvature observed at $-15^{\circ} \mathrm{C}$, which is considerably rounded. The average (failure) strains at peak stress corresponding to the various test temperatures is observed to be nearly independent of the test temperatures employed. Moreover, a shoulder/double-peak is consistently observed in the true stress versus true strain curves near the peak stress in tests ranging from $-50{ }^{\circ} \mathrm{C}$ to $-125^{\circ} \mathrm{C}$; however, the shoulder/double peak is absent at test temperatures of $-15{ }^{\circ} \mathrm{C},-150{ }^{\circ} \mathrm{C}$ and $-173{ }^{\circ} \mathrm{C}$. In all cases the shoulder/double-peak at peak stress is followed by a catastrophic drop in ice strength with the accumulation of inelastic strain.
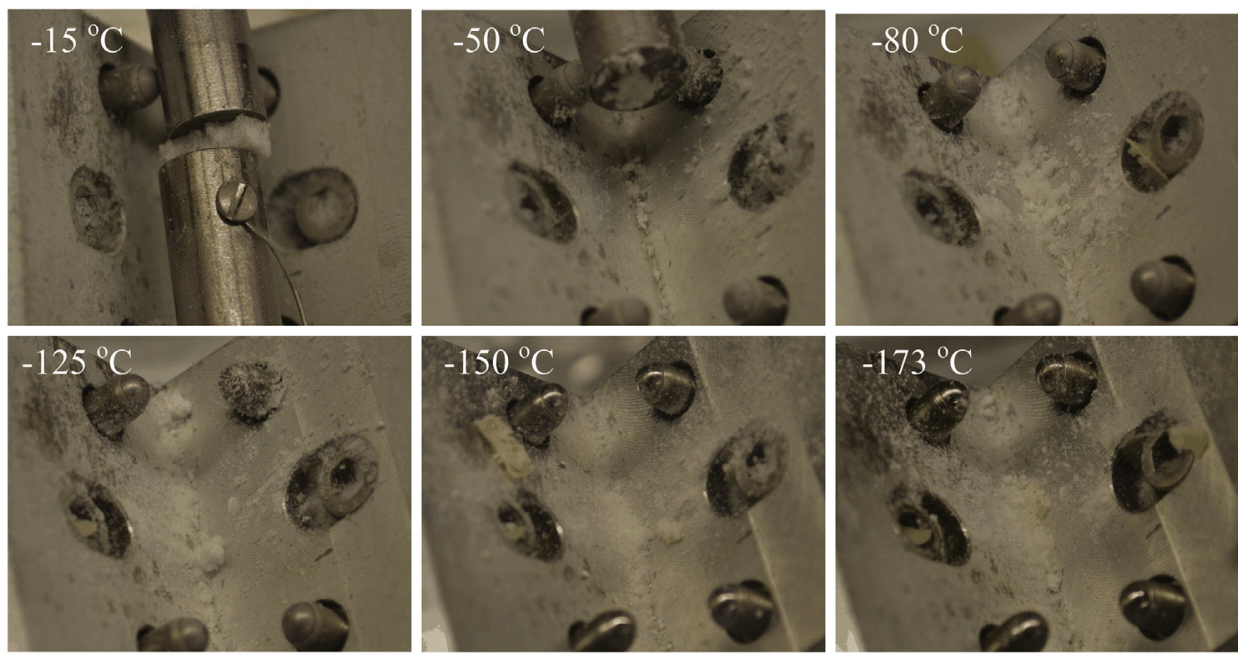


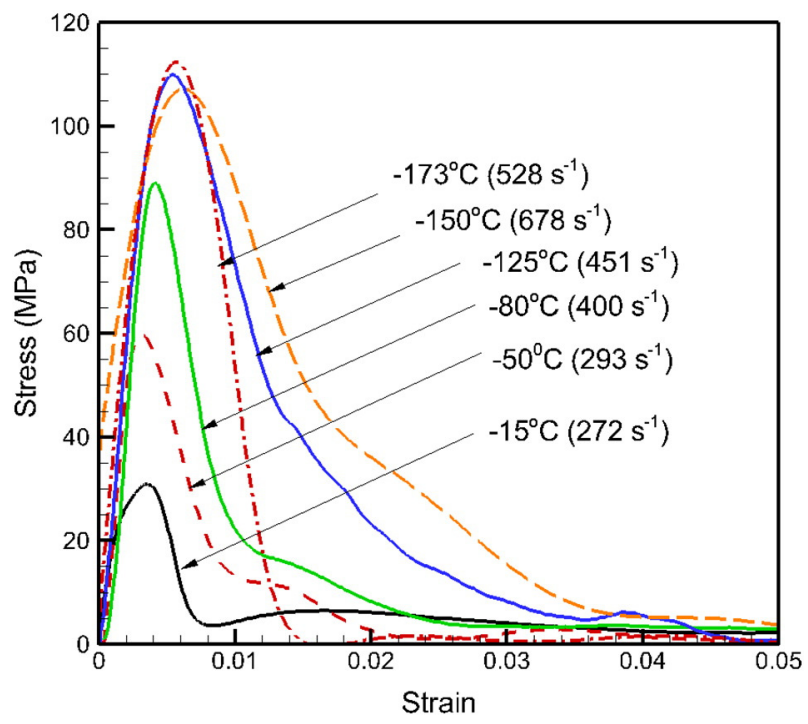

Fig. 23. Dynamic stress versus strain curves obtained for distilled water ice under dynamic uniaxial compression at test temperatures of $-15^{\circ} \mathrm{C},-50^{\circ} \mathrm{C},-80^{\circ} \mathrm{C},-125^{\circ} \mathrm{C},-150{ }^{\circ} \mathrm{C}$ and $-173{ }^{\circ} \mathrm{C}$.

The presence of the shoulder/double-peak is an indication that failure of the ice samples occurs at the peak stress by fracture into relatively large ice fragments, which remain essentially sandwiched in between the aluminum inserts and can carry substantial fraction of the peak compressive load before extensive fragmentation can occur in the test temperature range from $-50{ }^{\circ} \mathrm{C}$ to $-125^{\circ} \mathrm{C}$. The absence of the shoulder/ double peak at $-15{ }^{\circ} \mathrm{C}$ is attributed to the relative ductile failure of the ice samples during dynamic compression. Also, it is interesting to note that the dynamic stress versus strain curve corresponding to $-15{ }^{\circ} \mathrm{C}$ test temperature does not show a catastrophic drop in stress carrying capacity after the attainment of peak (failure) stress. In fact, after the attainment of peak stress the stress in the samples is observed to drop to a plateau characterized by a long tail, indicating the existence of substantial residual strength in the post peak-stress pulverized/ fragmented ice. Consequently, the residual strength of ice at $-15{ }^{\circ} \mathrm{C}$ in the post-peak regime can be best understood by considering the pulverized ice as an assemblage of wet highly fragmented granular material that is held together by ice melt created by adiabatic heating due to grain-to-grain frictional sliding in the post peak-stress regime. On the other hand, the absence of the double-peak at $-150{ }^{\circ} \mathrm{C}$ and $-173{ }^{\circ} \mathrm{C}$ can be attributed to extensive fragmentation and pulverization of the ice samples immediately following the attainment of peak stress during the dynamic compression event. The relatively smaller diameter steel inserts along with the fine scale pulverized ice, inhibit trapping of the ice fragments in between the loading faces of the inserts and subsequent reloading of the fractured ice.

Fig. 21 shows pictures of fragmented ice samples following dynamic uniaxial compression at test temperatures of $-15^{\circ} \mathrm{C},-50{ }^{\circ} \mathrm{C},-80^{\circ} \mathrm{C}$, $-125^{\circ} \mathrm{C},-150^{\circ} \mathrm{C}$ and $-173^{\circ} \mathrm{C}$, respectively. At all temperatures, except for at $-15{ }^{\circ} \mathrm{C},-50{ }^{\circ} \mathrm{C}$ and $-80{ }^{\circ} \mathrm{C}$ the ice samples are observed to form highly fragmented and dry (frozen) granular powder following dynamic compression. In the case of tests at $-15^{\circ} \mathrm{C}$ and $-50{ }^{\circ} \mathrm{C}$, the ice fragments were recovered as agglomerates of fine grained wet granular material.

Fig. 22 shows the summary of the logarithmic of peak stress as a function of logarithmic of strain rate obtained under dynamic compression on the ice samples at test temperatures of $-15^{\circ} \mathrm{C},-50^{\circ} \mathrm{C},-80^{\circ} \mathrm{C}$, $-125^{\circ} \mathrm{C},-150^{\circ} \mathrm{C}$ and $-173^{\circ} \mathrm{C}$. As seen from the figure, the peak stress (strength) of ice increases with decreasing test temperatures in the temperature range from $-15^{\circ} \mathrm{C}$ to $-125^{\circ} \mathrm{C}$ and with increasing strain rates in the strain rate range from 100 to $750 \mathrm{~s}^{-1}$. The sensitivity of peak stress to both test temperature and strain rate is observed to decrease with decreasing test temperatures. The peak stresses in the test temperature range from $-150{ }^{\circ} \mathrm{C}$ to $-173^{\circ} \mathrm{C}$ are observed to remain almost at the same level as those obtained at $-125^{\circ} \mathrm{C}$.

Comparing peak stress data obtained from the present dynamic uniaxial compression tests with those obtained from previous studies at quasi-static and high strain rates in the past, it can be argued that the results of Jones (1997), Schulson et al. (2005) and Shazly et al. (2006b, 2009) are consistent with results obtained in the present study and show similar positive rate effects over the strain rate range of $10^{-2}$ to $10^{3} \mathrm{~s}^{-1}$ at $-15^{\circ} \mathrm{C}$. The peak stress versus strain rate data obtained from the present study have almost the same slope as the results obtained by Jones (1997), Schulson et al. (2005) and Shazly et al. (2006b, 2009) on distilled water ice at approximately $-10{ }^{\circ} \mathrm{C}$, except that the peak stresses obtained in the present study are a little higher than those reported in the studies by Shazly et al. (2006b, 2009). It is to be note that the results of Schulson (1990) at strain rate $1 \times 10^{-3} \mathrm{~s}^{-1}$ and Arakawa and Maeno (1997) at $4 \times 10^{-5} \mathrm{~s}^{-1}$ show similar effects of temperature with decreasing test temperatures. Also, the peak strength of ice in the temperature range from $-100{ }^{\circ} \mathrm{C}$ to $-130{ }^{\circ} \mathrm{C}$ is almost at the same level and the strength is observed to increase with decreasing test temperatures down to $-173^{\circ} \mathrm{C}$, which is similar to the results obtained at much higher loading rates in the present study. The dependence of peak stress on strain rate for uniaxial compression of distilled water ice at test temperatures of $-15{ }^{\circ} \mathrm{C},-50{ }^{\circ} \mathrm{C}$ and $-80{ }^{\circ} \mathrm{C}$ can be described by the relationships $\sigma=7.2 \dot{\varepsilon}^{0.27}$ with a correlation coefficient of $r^{2}=0.8, \sigma=18.0 \dot{\varepsilon}^{0.2}$ with a correlation coefficient of $r^{2}=0.3, \sigma=24.5 \dot{\varepsilon}^{0.2}$ with a correlation coefficient of $r^{2}=0.35$, and $\sigma=57.1 \dot{\varepsilon}^{0.1}$ with a low correlation coefficient of $r^{2}=0.07$, respectively.

Fig. 23 shows a summary of the stress versus strain profiles under dynamic compression of ice at test temperatures of $-15^{\circ} \mathrm{C},-50{ }^{\circ} \mathrm{C}$, $-80{ }^{\circ} \mathrm{C},-125{ }^{\circ} \mathrm{C},-150{ }^{\circ} \mathrm{C}$ and $-173^{\circ} \mathrm{C}$. The corresponding strain rates in the tests varied from $272 / \mathrm{s}$ to $678 / \mathrm{s}$. From the figure it can be seen that the peak stress (strength) of ice increases with decreasing temperature as the test temperature is lowered from $-15{ }^{\circ} \mathrm{C}$ to $-125^{\circ} \mathrm{C}$. The observed peak stress in the temperature range $-125^{\circ} \mathrm{C}$ to $-173^{\circ} \mathrm{C}$ is essentially constant and lies in a narrow band of 110 to $120 \mathrm{MPa}$. These results along with the results shown in Fig. 22 help to better clarify the strain-rate and temperature dependency of peak stress in ice.

\section{Acknowledgments}

The authors acknowledge financial support from NASA under contract NNX13A74A and National Natural Science Foundation of China (Grant No. 11402277).

\section{Appendix A}

Analysis of uniform uniaxial compression of solid cylinders under the presence of frictional forces has shown that the radial stress $\sigma_{r r}$ is given by (Kuhn, 2000)

$\sigma_{r r}=f \frac{d}{L}\left(1-\frac{2 r}{d}\right)$

where $f$ is the frictional stress and is assumed to be constant across the cross-sectional area of the specimen. In general, the radial stress $\sigma_{r r}$ can be minimized by decreasing the frictional stresses and/or the ratio $\mathrm{d} / \mathrm{L}$. Recent experiments on the frictional behavior of ice against various materials (Kennedy et al., 2000 4231; Maeno and Arakawa, 2004; Maeno et al., 2003) showed that the coefficient of kinetic friction is reduced by a factor of 10 as the sliding velocity increases from $10^{-5}$ to $0.1 \mathrm{~m} / \mathrm{s}$. For the SHPB tests, assuming constant volume deformation, the radial 
velocity of the outside radius of the ice specimen is given by

$\frac{d r}{d t}=\frac{r_{i} \dot{\varepsilon}(t)}{(1-\varepsilon(t))^{3 / 2}}$

where $r_{i}$ is the initial outside radius, and $\varepsilon$ and $\_\dot{\varepsilon}$ are the instantaneous average strain- and strain-rates in the specimen, respectively. For the case of the experiment conducted at the lowest strain-rate, i.e., $100 \mathrm{~s}^{-1}$, and with an initial diameter of the specimen of $\sim 19.05 \mathrm{~mm}$, the radial component of the particle velocity at the outside diameter of the specimen at the peak stress is approximately $\sim 1 \mathrm{~m} / \mathrm{s}$. This velocity is expected to reduce the coefficient of kinetic friction of ice from approximately 0.06 (Maeno et al., 2003) by a factor of 10 , thus negating any effects of friction.

\section{References}

Arakawa, M., Maeno, N., 1997. Mechanical strength of polycrystalline ice under uniaxial compression. Cold Reg. Sci. Technol. 26, 215-229.

Carr, M.H., Belton, M.J.S., Chapman, C.R., Davies, M.E., Geissler, P., Greenberg, R., McEwen, A.S., Tufts, B.R., Greeley, R., Sullivan, R., 1998. Evidence for a subsurface ocean on Europa. Nature 391 (6665), 363-365.

Carter, D., Michel, B., Michel, B., 1971. Lois et mecanismes de l'apparente fracture fragile de la glace de riviere et de lac. Universite Laval, Section Mecanique des Glaces.

Currier, J.H., Schulson, E.M., 1982. The tensile strength of ice as a function of grain size. Acta Metall. 30 (8), 1511-1514.

Davies, E.D.H., Hunter, S.C., 1963. The dynamic compression testing of solids by the method of the split Hopkinson pressure bar. J. Mech. Phys. Solids 11 (3), 155-179.

Dempsey, J.P., 1991. The fracture toughness of ice. Ice-Structure Interaction. Springer, pp. $109-145$.

Dempsey, J.P., Adamson, R.M., Mulmule, S.V., 1999a. Scale effects on the in-situ tensile strength and fracture of ice. Part II: First-year sea ice at Resolute, NWT. Int. J. Fract. 95 (1-4), 347-366.

Dempsey, J.P., Defranco, S.J., Adamson, R.M., Mulmule, S.V., 1999b. Scale effects on the insitu tensile strength and fracture of ice. Part I: Large grained freshwater ice at Spray Lakes Reservoir, Alberta. Int. J. Fract. 95 (1-4), 325-345.

Dutta, P.K., 1993. Compressive failure of polycrystalline ice under impact. In: Chung, J.S (Ed.), Proceedings of the Third (1993) International Offshore and Polar Engineering Conference. The International Society of Offshore and Polar Engineers, Singapore, pp. 573-580.

Dutta, P.K., Cole, D.M., Schulson, E.M., Sodhi, D.S., 2004. A fracture study of ice under high strain rate loading. Int. J. Offshore Polar Eng. 14 (3), 182-188.

Frew, D., Forrestal, M., Chen, W., 2002. Pulse shaping techniques for testing brittle materials with a split Hopkinson pressure bar. Exp. Mech. 42 (1), 93-106.

Graham, D.A., 1989. Specimen inertia in high strain-rate compression. J. Phys. D 22 , $1888-1893$.

Haynes, F.D., 1978. Effect of temperature on the strength of snow-ice. CRREL-78-27.

Hopkinson, B., 1914. A method of measuring the pressure produced in the detonation of high explosives or by the impact of bullets. Philos. Trans. R. Soc. Lond. Ser. A 213, 437-456.

Irfan, M.A., Prakash, V., 1994. Contact temperatures during sliding in pressure shear impact. Proceedings Society of Experimental Mechanics Conference. SEM, Bethel, CT, Baltimore, MD, pp. 173-182.

Jones, S.J., 1997. High strain-rate compression tests on ice. J. Phys. Chem. B 101 (32), 6099-6101.

Jones, S.J., Glen, J.W., 1969. The mechanical properties of single crystals of pure ice. J. Glaciol. 8, 463-473.

Kennedy, F.E., Schulson, E.M., Jones, D.E., 2000. The friction of ice on ice at low sliding velocities. Philos. Mag. A Phys. Condens. Matter Struct. Defects Mech. Prop. 80 (5), 1093-1110.

Kim, H., Keune, J.N., 2007. Compressive strength of ice at impact strain rates. J. Mater. Sci. 42, 2802-2006.
Klug, D.D., 2002. Condensed-matter physics: dense ice in detail. Nature 420 (6917), 749-751.

Kolsky, H., 1949. An investigation of the mechanical properties of materials at very high rates of loading. Proc. Phys. Soc. Sect. B 62 (11), 676-700.

Kuhn, H.A., 2000. Universal compression testing, mechanical testing and evaluation, ASM Handbook. ASM Handbook. ASM International, Materials Park, OH, pp. 143-151.

Maeno, N., Arakawa, M., 2004. Adhesion shear theory of ice friction at low sliding velocities, combined with ice sintering. J. Appl. Phys. 95 (1), 134-139.

Maeno, N., Arakawa, M., Yasutome, A., Mizukami, N., Kanazawa, S., 2003. Ice-ice friction measurements, and water lubrication and adhesion-shear mechanisms. Can. J. Phys. 81 (1-2), 241-249.

Nixon, W.A., Schulson, E.M., 1987. A micromechanical view of the fracture-toughness of ice. J. Phys. 48 (C-1), 313-319.

Okada, M., Liou, N.-S., Prakash, V., Miyoshi, K., 2001. Tribology of high speed metal-onmetal sliding at near-melt and fully-melt interfacial temperatures. Wear 249, 672-686.

Parameswaran, V.R., Jones, S.J., 1975. Brittle fracture of ice at 77 K. J. Glaciol. 14 (71), 305-315.

Petrenko, V.F., Whitworth, E.W., 1999. Physics of Ice. Oxford University Press, New York, NY.

Prakash, V., Yuan, F., 2004. Results of a pilot study to investigate the feasibility of using new experimental techniques to measure sliding resistance at seismic slip rates. EOS Trans. AGU, Fall Meeting Supplement. AGU, San Francisco, CA (pp. Abstract T21D-02).

Sarva, S., Nemat-Nasser, S., 2001. Dynamic compressive strength of silicon carbide under uniaxial compression. Mater. Sci. Eng., A 317 (1-2), 140-144.

Schulson, E.M., 1990. The brittle compressive fracture of ice. Acta Metall. Mater. 38 (10), 1963-1976.

Schulson, E.M., 2001. Brittle failure of ice. Eng. Fract. Mech. 68 (17-18), 1839-1887.

Schulson, E.M., Duval, P., 2009. Creep and Fracture of Ice. Cambridge University Press, New York.

Schulson, E.M., Gratz, E.T., 1999. The brittle compressive failure of orthotropic ice under triaxial loading. Acta Mater. 47 (3), 745-755.

Schulson, E.M., Iliescu, D., Fortt, A., 2005. Characterization of ice for return-to flight of the space shuttle: part i-hard ice. NASA Contractor Report, 213643.

Shan, R.L., Jiang, Y.S., Li, B.O., 2000. Obtaining dynamic complete stress-strain curves for rock using the split Hopkinson pressure bar technique. J. Rock Mech. Min. Sci. 37 (6), 983-992

Shazly, M., Prakash, V., Lerch, B., 2006a. High strain-rate compression testing of ice. E-15282; NASA TM-2006-213966. NASA Glenn Research Center, Cleveland, OH.

Shazly, M., Prakash, V., Lerch, B.A., 2006b. High-Strain-Rate Compression Testing of Ice. National Aeronautics and Space Administration, Glenn Research Center.

Shazly, M., Prakash, V., Lerch, B.A., 2009. High strain-rate behavior of ice under uniaxial compression. Int. J. Solids Struct. 46 (6), 1499-1515.

Sunny, G., Prakash, V., Lewandowski, J.J., 2007. Effects of annealing and specimen geometry on dynamic compression of a Zr-based bulk metallic glass. J. Mater. Res. 22 (2), 389-401.

Sunny, G., Yuan, F., Prakash, V., Lewandowski, J.J., 2008. Effect of high strain rates on peak stress in a Zr-based bulk metallic glass. J. Appl. Phys. 104, 093522.

Sunny, G., Yuan, F., Prakash, V., Lewandowski, J.J., 2009. Design of inserts for splitHopkinson pressure bar testing of low strain-to-failure materials. Exp. Mech. 49 (4), 479-490.

Uchida, T., Kusumoto, S., 1999. Effects of test conditions on fracture toughness and fracture morphology of polycrystalline ice. JSME Int J., Ser. A 42 (4), 601-609.

Weber, L.J., Nixon, W.A., 1996. Fracture toughness of freshwater ice-part I: experimental technique and results. J. Offshore Mech. Arct. Eng. 118 (2), 135-140.

Wu, X., Prakash, V., 2015. Dynamic strength of distill water and lake water ice at high strain rates. Int. J. Impact Eng. 76, 155-165.

Yuan, F., Prakash, V., 2008a. Slip weakening in rocks and analog materials at co-seismic slip rates. J. Mech. Phys. Solids 56, 542-560.

Yuan, F., Prakash, V., 2008b. Use of a modified Torsional Kolsky bar to study frictional slip resistance in rock analog materials at co-seismic slip rates. Int. J. Solids Struct. 45 (14-15), 4247-4263.

Yuan, F., Prakash, V., Tullis, T., 2011. Origin of pulverized rocks during earthquake fault rupture. J. Geophys. Res. 116 (B06309). 